\title{
Transcriptomic Profiling of MDA-MB-231 Cells Exposed to Boswellia Serrata and 3-O-Acetyl-B-Boswellic Acid; ER/UPR Mediated Programmed Cell Death
}

\author{
ELIZABETH A. MAZZIO, CHARLES A. LEWIS and KARAM F.A. SOLIMAN \\ College of Pharmacy \& Pharmaceutical Sciences, Florida A \& M University, Tallahassee, FL, U.S.A.
}

\begin{abstract}
Background/Aim: Triple-negative breast cancer $(T N B C)$ is characterized by the absence of hormone receptors (estrogen, progesterone and human epidermal growth factor receptor-2) and a relatively poor prognosis due to inefficacy of hormone receptor-based chemotherapies. It is imperative that we continue to explore natural products with potential to impede growth and metastasis of TNBC. In this study, we screened over 1,000 natural products for capacity to induce cell death in TNBC (MDA-MB -231) cells. Materials and Methods: Frankincense (Boswellia serrata extract (BSE)) and 3-O-Acetyl- $\beta$-boswellic acid (3-OA $\beta B A$ ) were relatively potent, findings that corroborate the body of existing literature. The effects of $B S E$ and 3-OA $\beta B A$ on genetic parameters in MDA-MB-231 cells were evaluated by examining whole-transcriptomic influence on $m R N A$ s, long intergenic non-coding RNA transcripts (lincRNA) and noncoding miRNAs. Results: Bio-statistical analysis demarcates the primary effect of both BSE/3-OA $\beta B A$ on the upregulation of PERK (protein kinase RNA-like endoplasmic reticulum kinase)- endoplasmic reticulum (ER)/unfolded protein response (UPR) pathways that are closely tied to activated programmed cell death (APCD). Global profiling confirms concomitant effects of BSE/3-OA $\beta B A$ on upwardly expressed ER/URP APCD key components PERK (EIF2AK3), XBP1, C/EBP homologous protein transcription
\end{abstract}

This article is freely accessible online.

Correspondence to: Prof. Karam F.A. Soliman Professor \& RCMI Program Director, College of Pharmacy \& Pharmaceutical Sciences, Florida A\&M University, Room 104 Dyson Pharmacy Building, 1520 ML King Blvd, Tallahassee, FL 32307, U.S.A. Tel: +1 8505993306, Fax: +1 8505993667, e-mail: karam.soliman@famu.edu

Key Words: Boswellic acid, Boswellia, apoptosis, Frankincense, cancer, microarray, endoplasmic reticulum, UPR, CHOP, ATF, ER, PERK, CHAC1, SESN2, TG2, sestrin, dual specificity phosphatase, histone cluster, epigenetics. factor (CHOP), ATF3 and DDIT3,4/DNA-damage-inducible transcript 3,4 (GADD34). Further, BSE and/or 3-OA $\beta B A$ significantly down-regulated oncogenes (OG) which, heretofore, lack functional pathway mapping, but are capable of driving epithelial-mesenchymal transition (EMT), cell survival, proliferation, metastasis and drug resistance. Among these are cell migration-inducing protein hyaluronan binding (CEMIP) [-7.22]; transglutaminase 2 [-4.96], SRY box 9 (SOX9) [-4.09], inhibitor of DNA binding 1, dominant negative helix-loop-helix protein (ID1) [-6.56]; and endothelin 1 (EDN1, [-5.06]). Likewise, in the opposite manner, BSE and/or 3-OA $B B A$ induced the robust overexpression of tumor suppressor genes (TSGs), including: glutathione-depleting ChaC glutathione-specific gammaglutamylcyclotransferase 1 (CHAC1) [+21.67]; the mTOR inhibitors - sestrin 2 (SESN2) [+16.4] Tribbles homolog 3 (TRIB3) [+6.2], homocysteine-inducible, endoplasmic reticulum stress-inducible, ubiquitin-like domain member 1 (HERPUD1) [+12.01]; and cystathionine gamma-lyase (CTH) [+11.12]. Conclusion: The anti-cancer effects of the historically used frankincense sap (BSE) appear to involve major impact on the ER/UPR response, concomitant to effecting multiple targets counter to the growth, proliferation and metastasis of TNBC cancer cells. The microarray data are available at Expression Omnibus GEO Series accession number GSE102891.

Frankincense has been used as a valuable multi-purpose natural product for over 5,000 years, where its medicinal form is derived from the tree sap resin of diverse species from the genus Boswellia/family Burseraceae. Its extended historical use reflects valuable insight about its properties from our ancestors who had a greater dependency on natural medicines. In the past century, with the rapid development of synthetic medicines, botanical therapeutics are perceived as menial compared to that of current medical treatment. Yet, at the same time, scientific literature continues to report Boswellia and its active component: boswellic acid can exert 
diverse antitumor properties (1) with the capacity to attenuate proliferation, angiogenesis, invasion and metastasis in established models (2-7).

With the availability of current biotechnologies, it is evident that Boswellia can mediate anti-cancer effects through direct reduction of pro-oncogenic proteins and transcription factors that otherwise drive aggressive malignancies. Just for a few examples, Boswellia and its constituents suppress NFкB, Bcl-2, bcl-xL, Mcl-1, IAP-1, BIRC5, VEGF (2, 8, 9) mPGES-1, MMP-2,7,9, PGE2 (5) cyclin D1, PCNA, c-Myc (10), cyclin E, CDK 2 and 4 and retinoblastoma (Rb) (11). Central to these effects are control over STAT3 phosphorylation of Jak $2 / \mathrm{Src}$ or Akt/GSK3 $\beta$ signaling tantamount to triggering apoptotic pathways through caspase9 , caspase-3, and cleaved PARP $(12,13)$. Other reported anticancer attributes of Boswellia include its potential to block the development of chemically induced cancers such as that by azomethane (14), prevent multidrug resistance (15) and act as a chemo-sensitizing agent $(4,16)$. These effects are consistently observed both in in vitro and in vivo (10). With regards to triple negative breast cancer (TNBC), Boswellia serrata extract (BSE) and 3-O-Acetyl- $\beta$-boswellic acid (3$\mathrm{OA} \beta \mathrm{BA}$ ) are equally effective against its growth and that of other malignant breast tumor cell lines $(8,17,18)$.

Here, we further investigate precipitating transcriptome changes induced by Boswellia serrata extract and 3-OA $\beta \mathrm{BA}$, in order to determine the major cause of cell death in TNBC breast cancer cells. These findings can serve as a general directive in future studies investigating the anti-cancer properties of frankincense.

\section{Materials and Methods}

Hanks Balanced Salt Solution, (4-(2-hydroxyethyl)-1-piperazineethanesulfonic acid) (HEPES), absolute ethanol $\geq 99.8 \%, 96$ well plates, pipette tips, Dulbecco's modified Eagle's medium (DMEM), fetal bovine serum (FBS), penicillin/streptomycin general reagents and supplies were all purchased from Sigma-Aldrich Co. (St. Louis, MO, USA) and VWR International (Radnor, PA, USA). Triplenegative human breast tumor (MDA-MB-231) cells were obtained from the American Type Culture Collection (Rockville, MD, USA). Boswellia serrata was obtained from Starwest Botanicals (Sacramento, CA, USA) and 3-O-Acetyl- $\beta$-boswellic acid was purchased from Cayman Chemical (Ann Arbor, MI, USA). All microarray equipment, reagents and materials were purchased from Affymetrix/ Thermo Fisher (Waltham, MA, USA).

All natural chemicals, reference drugs and (3-OA $\beta$ BA) were dissolved in DMSO [5-20 $\mathrm{mg} / \mathrm{mL}]$, where the crude herbs including Boswellia serrata were prepared in absolute ethanol $[50 \mathrm{mg} / \mathrm{mL}]$ after being diced, macerated and powdered prior to being stored at $-20^{\circ} \mathrm{C}$. All dilutions were prepared in sterile HBSS $+5 \mathrm{mM}$ HEPES, adjusted to a $\mathrm{pH}$ of 7.4, ensuring solvent concentration of DMSO or absolute ethanol at less than $0.5 \%$.

Cell culture. MDA-MB-231 cells were cultured in $175 \mathrm{~cm}^{2}$ flasks containing DMEM supplemented with $10 \%$ FBS and $100 \mathrm{U} / \mathrm{ml}$ penicillin $\mathrm{G}$ sodium $/ 100 \mu \mathrm{g} / \mathrm{ml}$ streptomycin sulfate. Cells were grown at $37^{\circ} \mathrm{C}$ in $5 \% \mathrm{CO}_{2} /$ atmosphere and sub-cultured every three to five days.

Cell viability assay. Alamar Blue cell viability assay was used to determine cytotoxicity. Viable cells are capable of reducing resazurin to resorufin (a detectable fluoroprobe). Briefly, 96-well plates were seeded with MDA-MB-231 cells at a density of $5 \times 10^{6}$ cells $/ \mathrm{ml}$. Cells were treated with HBSS (control) and various concentrations of Boswellia serrata extract or 3-O-Acetyl- $\beta$ boswellic acid for $24 \mathrm{~h}$ at $37^{\circ} \mathrm{C}, 5 \% \mathrm{CO}_{2}$ in atmosphere. Alamar blue $(0.1 \mathrm{mg} / \mathrm{ml}$ in HBSS $)$ was added at $15 \% \mathrm{v} / \mathrm{v}$ to each well, and the plates were incubated for 6-8 h. Quantitative analysis of dye conversion was measured on a Synergy ${ }^{\mathrm{TM}}$ HTX Multi-Mode microplate reader (BioTek, Winooski, VT, USA), 550nm $/ 580 \mathrm{~nm}$ (excitation/emission). The data were expressed as a percentage of untreated controls.

Fluorescence microscopy. Live cell imaging was conducted using Fluorescein diacetate (FDA), which is a cell-permeable esterase substrate. The fluorescein molecule accumulates in cells that possess intact membranes, serving as a marker of cell viability. Briefly, FDA was dissolved in ethanol $4.2 \mathrm{mg} / \mathrm{ml}$ and subsequently prepared at $20 \mu \mathrm{M}$ in HBSS. After $30 \mathrm{~min}$ of incubation, samples were analyzed photographically using a fluorescent /inverted microscope, CCD camera and data acquisition by ToupTek View (ToupTek Photonics Co, Zhejiang, P.R. China).

Microarray WT 2.1 human datasets. After treatment, cells were washed three times in HBSS, rapidly frozen and stored at $-80^{\circ} \mathrm{C}$. Total RNA was isolated/ purified using the TRIzol/chloroform method, quality was assessed and concentration was equalized to $82 \mathrm{ng} / \mu \mathrm{l}$ in nuclease free water. Whole transcriptome analysis was conducted according to the GeneChip ${ }^{\mathrm{TM}}$ WT PLUS Reagent Manual for Whole Transcript (WT) Expression Arrays. Briefly, RNA was synthesized to first strand cDNA, second-strand cDNA, followed by transcription to cRNA. cRNA was purified and assessed for yield, prior to 2nd cycle single stranded cDNA synthesis, hydrolysis of RNA and purification of 2 nd cycle single stranded cDNA. cDNA was then quantified for yield and equalized to $176 \mathrm{ng} / \mathrm{ml}$. Subsequently, cDNA was fragmented, labeled and hybridized on to the arrays prior to being subjected to fluidics and imaging using the Gene Atlas (Affymetrix, ThermoFisher Scientific, Waltham, MA, USA).

The array data quality control and initial processing from CEL to CHP files were conducted using expression console, prior to data evaluation using the Affymetrix transcriptome analysis console. Supportive analysis was accomplished using geneontology.org (19) and DAVID Bioinformatics Resources 6.8 National Institute of Allergy and Infectious Diseases (NIAID), NIH (20).

Microarray miRNA 4.1 human datasets. miRNA was isolated using the QIAzol reagent and miRNeasy Mini Kit (Qiagen, Germantown, MD). Briefly, after RNA purification, samples were labeled with a POLY A tail, and ligated using a flash tag ligation mix from the FlashTag $^{\text {TM }}$ Biotin HSR RNA kit (Affymetrix). Subsequently, biotin labeled RNA was detected using streptavidin - EP and hybridized onto a Genechip miRNA 4.1 human array, prior to fluidics and imaging by the Gene Atlas. The array data quality control and initial processing from CEL to CHP files were conducted using expression console, prior to data evaluation using the transcriptome analysis console provided 


\section{HTP screening of natural chemicals / botanical extracts : Toxicity of MDA-MB-231 cells}
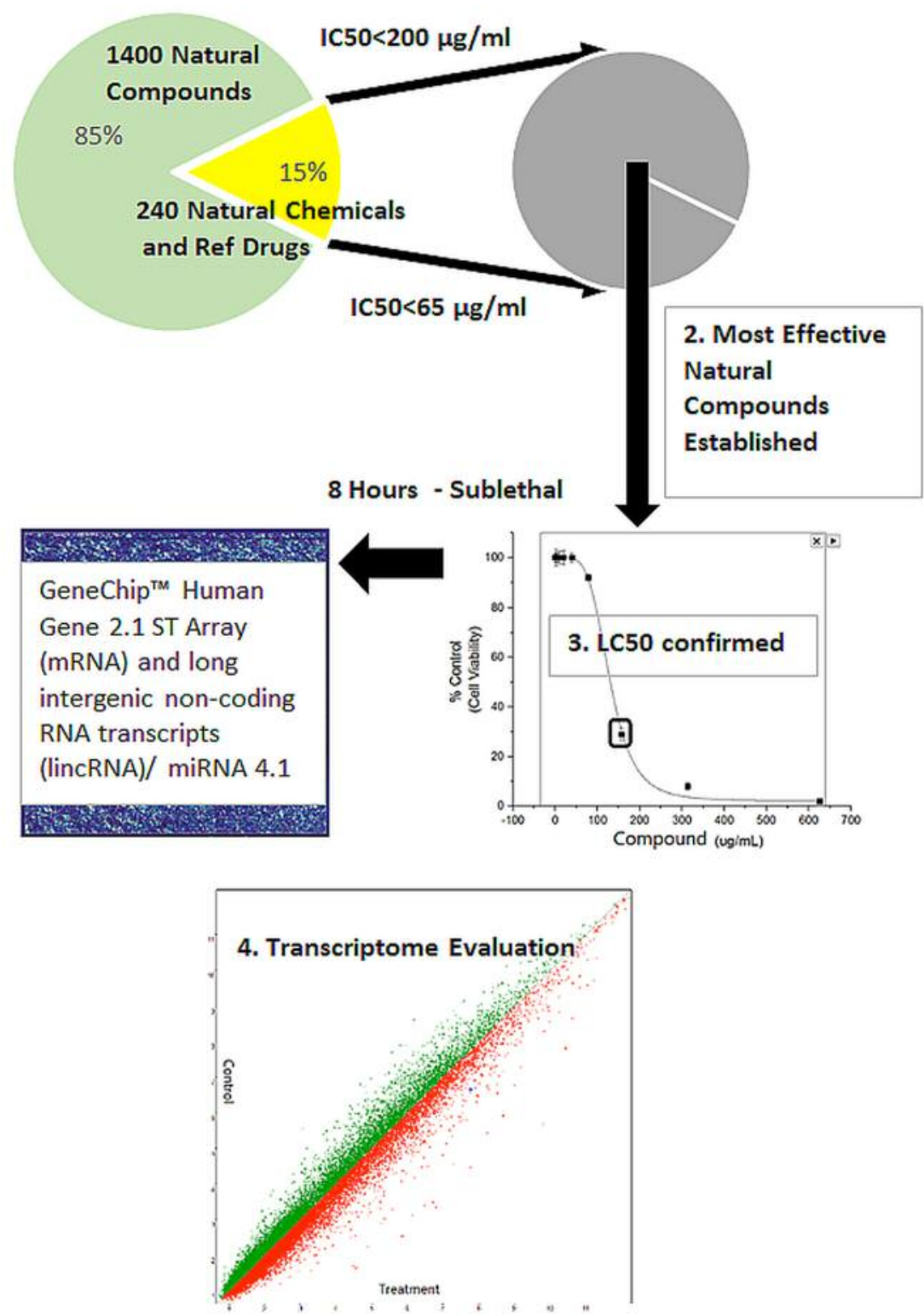

Figure 1. Natural compound screening procedure: A total of 240 in -house natural plant-derived chemicals $(<65 \mu \mathrm{g} / \mathrm{ml})$ and 1,400 botanical herbs $(<200 \mu \mathrm{g} / \mathrm{ml})$ were tested for capacity to induce cytotoxicity on MDA-MB-231 cells, relative to chemotherapy drugs. Lead compounds Frankincense (Boswellia serrata extract (BSE)) and 3-O-Acetyl- $\beta$-boswellic acid (3-OA $\beta B A$ ) were then cultured for 8 hours at the LC $C_{50}$, prior to cell death-and immediately frozen at $-80^{\circ} \mathrm{C}$. Microarray analysis was performed to identify biological influence on the entire transcriptome.

by Affymetrix. Supportive analysis was accomplished using geneontology.org (19) and DIANA miRPath tools $(21,22)$.

Data analysis. Statistical analysis was performed using Graph Pad Prism (version 3.0; Graph Pad Software Inc. San Diego, CA, USA) with significance of difference between the groups assessed using a one-way ANOVA, then followed by a Tukey post hoc means comparison test, or a Student's $t$-test. $\mathrm{LC}_{50} \mathrm{~s}$ were determined by regression analysis using Origin Software (Origin Lab, Northampton, MA, USA). 


\section{Cytotoxic effects of Boswellia Serrata on MDA-MD-231 Cells}



Figure 2. Cytotoxic effects of Boswellia serrata (BSE) on MDA-MB-231 cells at 24 h of incubation at $37^{\circ} \mathrm{C}, 5 \% \mathrm{CO}_{2} / \mathrm{Atm}^{\mathrm{T}}$. The data reflect loss of cell viability using FDA which is cleaved only by viable cells. (A) Untreated Control (B) $156 \mu \mathrm{g} / \mathrm{ml}$ (C) $313 \mu \mathrm{g} / \mathrm{ml}$ (D) $626 \mu \mathrm{g} / \mathrm{ml}$.

\section{Results}

A high throughput (HTP) screening module is routinely used in our facility to enable the preliminary evaluation of thousands of herbs and plant chemicals on selective targets, and in this case for relative capacity to induce cell death in MDA-MB-231 cells (Figure 1). Briefly, $\mathrm{LC}_{50} \mathrm{~s}$ were established, natural products were ranked for potency and lead compounds identified. Here we focus on the natural herb: Boswellia serrata (BSE), where we present fluorescence FDA staining showing a loss of viability over concentration (Figure 2) and corresponding cytotoxicity as determined by Alamar Blue (Figure 3). The $\mathrm{LC}_{50}$ s were determined $(128.8 \mu \mathrm{g} / \mathrm{ml})$ for BSE and its active component 3-OAßBA (46.32 $\mu \mathrm{g} / \mathrm{ml})$ (Figure 4).

For whole transcriptome microarray studies, the $\mathrm{LC}_{50} \mathrm{~s}$ of BSE and 3-OAßBA were applied to fully viable cells at Time 0 (zero minutes), and morphological changes were monitored every hour, to ensure no cell death was evident. At 6-8 h, the cells retained morphological shape, flask attachment and had no obvious signs of cell death. At this point, cells were rapidly washed in HBSS $3 \mathrm{x}$, spun and frozen at $-80^{\circ} \mathrm{C}$. This time of acquisition was ascertained as appropriate to ensure capture of information on pivotal events elicited/precipitating cell death.

Using affymetrix human whole transcriptome arrays [GeneChip Human Gene Array 2.1], the data showed that of the 48226 transcripts tested, there were 300 differentially expressed genes (DEGs) for BSE (265 up-regulated/65 downregulated) and for 3-OAßBA: 931 DEGs (391 upregulated/540 down-regulated). An overview of the transcriptome data for BSE treatment are presented by a volcano plot (Figure 5) showing fold change (FC) vs. significance - then cross referenced to Table I, which presents the largest differentially expressed changes. An overview of microarray data for 3-OA $\beta$ BA treatments are presented by a similar volcano plot (Figure 6) also cross referenced to Table II, showing the largest differentially expressed changes. The data discussed in this publication have been deposited in NCBI's Gene Expression Omnibus and are accessible through GEO Series accession number GSE102891 located at https://www.ncbi.nlm.nih.gov/geo/query/acc.cgi?acc=GSE102 891.

The pathway of greatest impact for both BSE and 3-OA $\beta B A$ elucidated by the Affymetrix transcriptome analysis console, sorted by greatest relevance was up up-regulation of the photodynamic therapy unfolded protein response (Figure 7). 


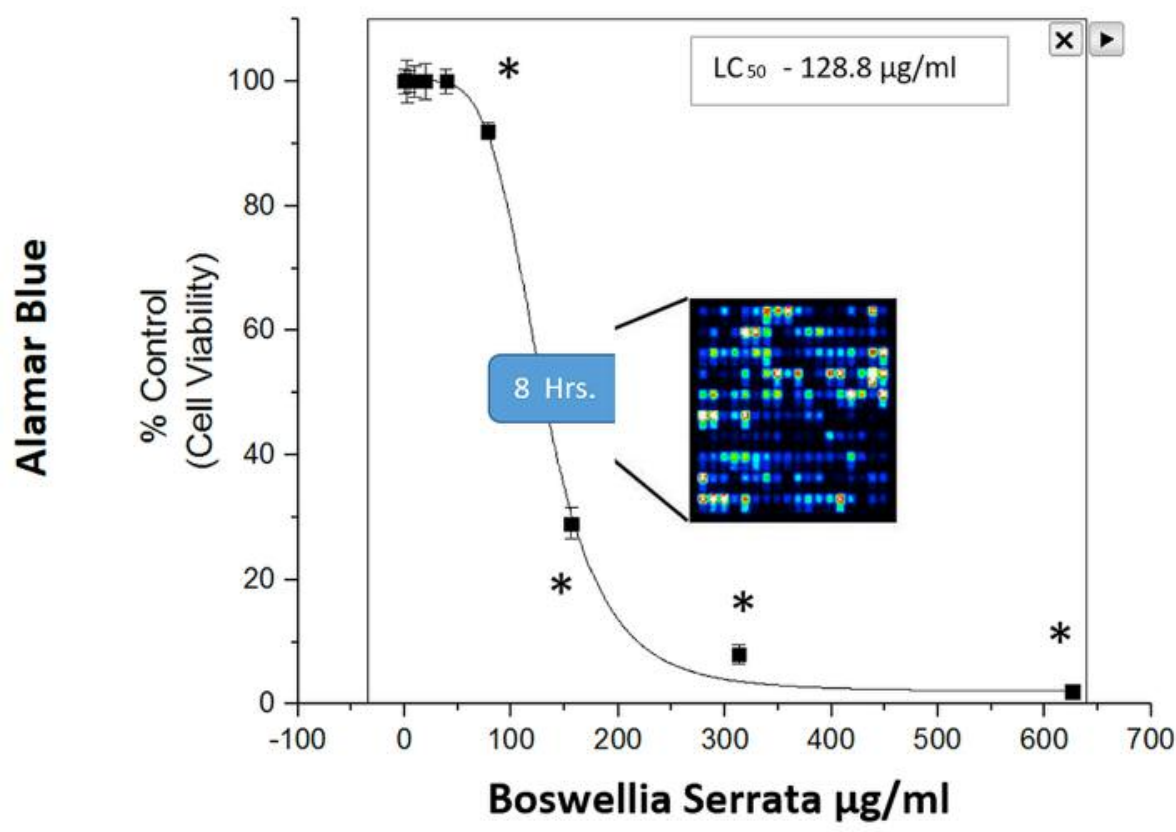

Figure 3. Cytotoxicity of BSE on MDA-MB-231 cells at $24 \mathrm{~h}$ of incubation at $37^{\circ} \mathrm{C}, 5 \% \mathrm{CO}_{2} / \mathrm{Atm}$. The data represent loss of viability as $\%$ control values as determined with Alamar Blue assay. The data are presented as the Mean $\pm S . E . M, n=4$, and significant difference from the controls were determined by a one-way ANOVA followed by a Tukey post hoc comparison test, * $p<0.05$.

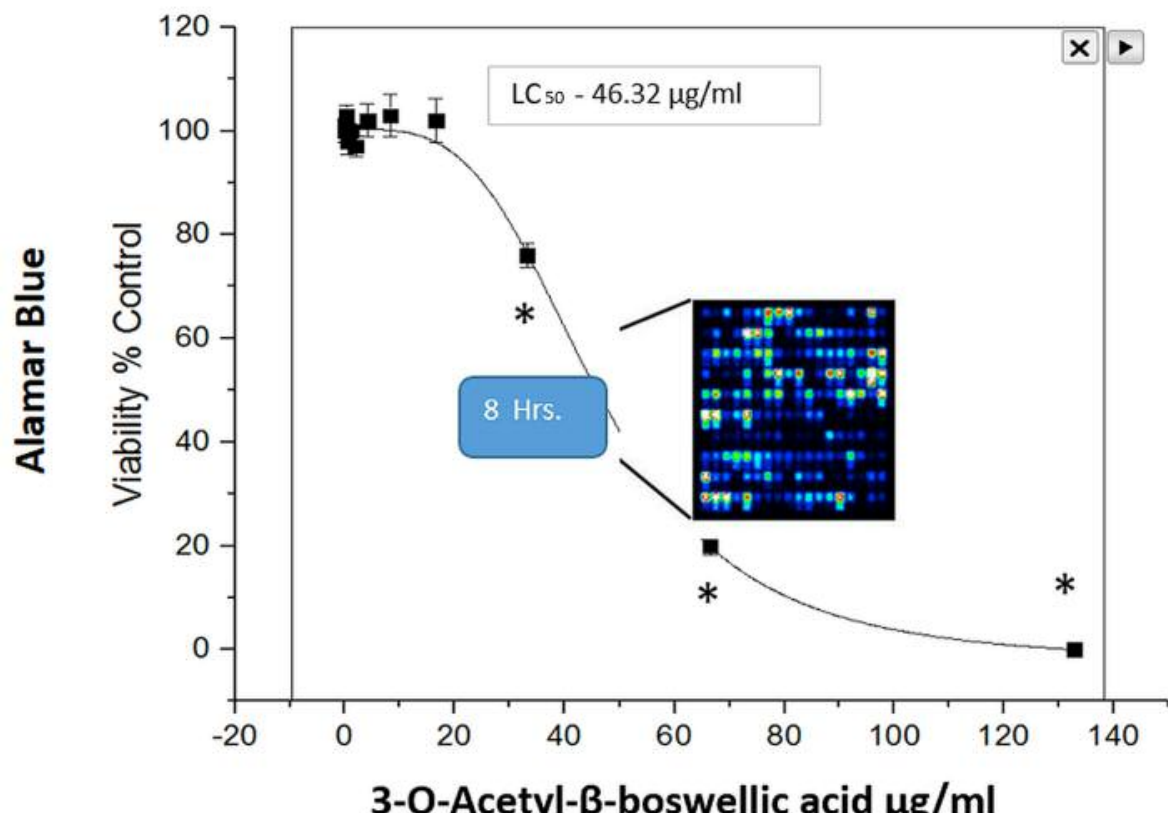

Figure 4. Cytotoxicity of 3-OA $\beta B A$ on $M D A-M B-231$ cells at $24 \mathrm{~h}$ of incubation at $37^{\circ} \mathrm{C}, 5 \% \mathrm{CO}_{2} / \mathrm{Atm}$. The data represent loss of viability as $\%$ Control values as determined with Alamar Blue assay. The data are presented as the mean $\pm S . E . M, n=4$, and significant differences from the controls were determined by a one-way ANOVA followed by a Tukey post-hoc comparison test, $* p<0.05$.

Using DAVID Functional Annotation Bioinformatics Microarray Analysis (20), we also found that the endoplasm reticulum was largely affected - up-regulated genes are shown on a KEGG overlay pathway map (Figure 8). Again, there was a very close overlay between BSE and 3-OA $\beta$ BA to elicit these ER mediated responses. In terms of dataset analysis for 


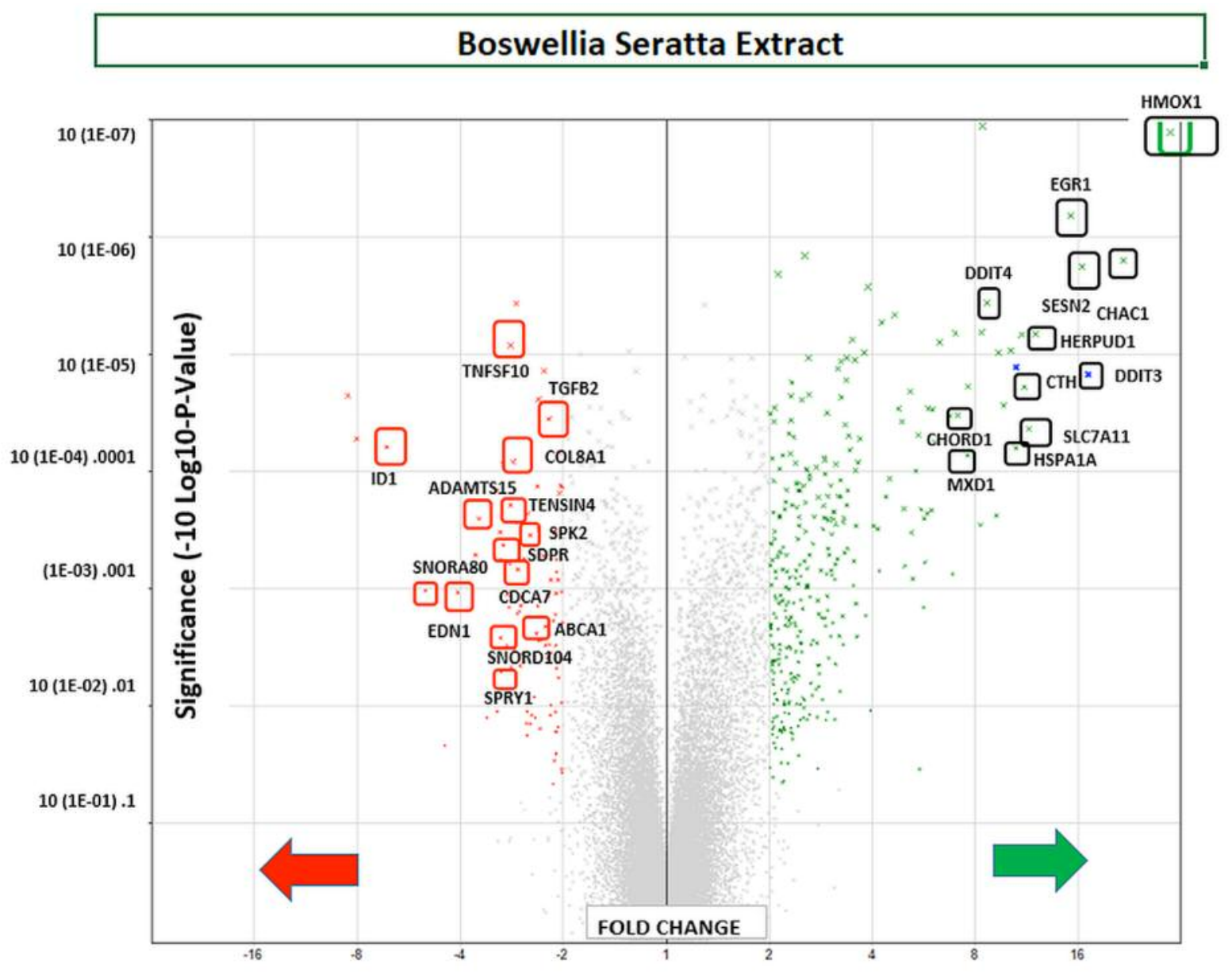

Figure 5. WT changes in BSE treated cells using GeneChip ${ }^{T M}$ Human Gene 2.1 ST Array. 48226 transcripts were tested, 300 differentially expressed genes (DEGs) were identified for (265 up-regulated/65 down-regulated). The data are presented by a volcano plot (fold-change by significance) for whole transriptome changes in BSE treated MDA-MB-231 cells vs. controls, $n=3$. The left panel shows down-regulated genes (red)/right panel (green) shows up-regulated genes: highlighting some of the highest differential changes, also listed in Table I.

functional biological relevance, we used geneontology.org enrichment analysis tool, which also confirms the findings from Affymetrix and David bio analytic tools, corroborating uniform up-regulation on the ER stress, unfolded protein responses as well as glucose depletion/starvation (Tables III and IV). Interestingly, very few changes were reported for the miRNAs, with reported pathways for hsa-miR-34b-3p (target of 14 genes) and hsa-miR-184 (target of 6 genes), as presented in Table V. These findings provide an overview of Boswellia seratta and its pharmacologically active compound, boswellic acid on the transcriptome of TNBCs.

\section{Discussion}

The data in this study suggest a primary mode of cell death by $3-\mathrm{OA} \beta \mathrm{BA}$ and $\mathrm{BSE}$ to involve ER stress leading to a UPR (unfolded protein response), this commonly associated with activated cell death. There has been a recent surge in research describing the importance of the ER/UPR in a variety of human pathologies, many of these relevant to cancer (23-25).

A literature review of the ER/UPR involvement in cancer unveils a scientific uncertainty and need for answers as to why activation of ER/UPR creates a double-edged sword. On the one hand, ER stress inducers (e.g. hypoxia, glucose, nutrient deprivation $(26,27)$ activate the ER/UPR which leads to tumor adaptation (a persistent elevation of prosurvival proteins, a resistance to chemotherapy, greater tumor progression, angiogenesis, invasion and thriving of dormant stem cells (28-30). Yet at the same time, activation of main pathways in the ER/UPR an also trigger programmed cell death (PCD) evidenced by many natural anti-cancer agents (31-41) alkylating/ platinum based drugs and anti-cancer steroids (42-47). Several articles have expressed the need for 
Mazzio et al: Whole-transcriptome Data Analysis of TNBC Cells Treated with 3-OA $\beta$ BA and BSE

Table I. Greatest transcriptome shifts incurred by BSE in MDA-MB-231 cells. The data represents signal, fold-change, p-Value, gene symbol and gene description. Top mRNA Changes: Affymetrix Microarray WT Human 2.1 ST

\begin{tabular}{|c|c|c|c|c|c|c|}
\hline Transcript & BSE & Control & Fold & ANOVA & Gene & Gene \\
\hline Cluster ID & $\begin{array}{l}\text { Bi-weighted } \\
\text { AVE Signal } \\
\text { Log2 }\end{array}$ & $\begin{array}{l}\text { Bi-weighted } \\
\text { AVE Signal } \\
\text { Log2 }\end{array}$ & Change & $p$-Value & Symbol & Description \\
\hline 16929562 & 9.61 & 4.71 & 29.8 & $<0.0001$ & HMOX1 & heme oxygenase 1 \\
\hline 16799739 & 8.54 & 4.1 & 21.67 & $<0.0001$ & $\mathrm{CHAC} 1$ & ChaC glutathione-specific gamma-glutamylcyclotransferase 1 \\
\hline 16766578 & 6.53 & 2.44 & 17.09 & $<0.0001$ & DDIT3 & DNA damage-inducible transcript 3 protein \\
\hline 16661544 & 8.05 & 4.02 & 16.4 & $<0.0001$ & SESN2 & Sestrin 2 \\
\hline 16989736 & 8.02 & 4.1 & 15.18 & $<0.0001$ & EGR1 & Early growth response 1 \\
\hline 16819325 & 9.53 & 5.95 & 12.01 & $<0.0001$ & HERPUD1 & Homocysteine-inducible, ER stress-inducible, ubiquitin-like DM1 \\
\hline 16979917 & 10.54 & 7.02 & 11.47 & $<0.0001$ & SLC7A11 & Solute carrier family 7 (anionic at light chain, xc- system), M 11 \\
\hline 16666055 & 7.26 & 3.78 & 11.12 & $<0.0001$ & $\mathrm{CTH}$ & Cystathionine gamma-lyase \\
\hline 16766588 & 4.98 & 1.59 & 10.54 & $<0.0001$ & MIR616 & MicroRNA 616; DNA-damage-inducible transcript 3 \\
\hline 17006863 & 10.83 & 7.44 & 10.51 & 0.0001 & HSPA1A & Heat shock $70 \mathrm{kDa}$ protein $1 \mathrm{~A}$; heat shock $70 \mathrm{kDa}$ protein $1 \mathrm{~B}$ \\
\hline 17006881 & 10.92 & 7.65 & 9.68 & $<0.0001$ & HSPA1B & Heat shock $70 \mathrm{kDa}$ protein $1 \mathrm{~B}$; heat shock $70 \mathrm{kDa}$ protein $1 \mathrm{~A}$ \\
\hline 16756202 & 8.57 & 5.37 & 9.2 & 0.0002 & EID3 & EP300 interacting inhibitor of differentiation 3 \\
\hline 16705961 & 8.87 & 5.8 & 8.41 & $<0.0001$ & DDIT4 & DNA damage inducible transcript 4 \\
\hline 16949264 & 5.58 & 2.53 & 8.28 & 0.0003 & LOC344887 & NmrA-like family domain containing 1 pseudogene \\
\hline 16881138 & 7.53 & 4.61 & 7.6 & $<0.0001$ & MXD1 & MAX dimerization protein 1 \\
\hline 16743222 & 8.18 & 5.35 & 7.11 & $<0.0001$ & CHORDC1 & Cysteine and histidine rich domain containing 1 \\
\hline 17083614 & 6.2 & 3.42 & 6.85 & 0.0008 & LURAP1L & Leucine rich adaptor protein 1-like \\
\hline 16998044 & 6.5 & 3.75 & 6.73 & $<0.0001$ & LUCAT1 & Lung cancer associated transcript 1 (non-protein coding) \\
\hline 16910609 & 7.81 & 5.16 & 6.28 & $<0.0001$ & TRIB3 & Tribbles pseudokinase 3 \\
\hline 16974968 & 6.03 & 3.42 & 6.1 & 0.0001 & SEL1L3 & Sel-1 suppressor of lin-12-like 3 (C. elegans) \\
\hline 17060061 & 7.75 & 5.16 & 6.01 & $<0.0001$ & ASNS & Asparagine synthetase (glutamine-hydrolyzing) \\
\hline 16739208 & 8.05 & 5.48 & 5.95 & 0.0002 & FTH1 & Ferritin, heavy polypeptide 1 \\
\hline 16705551 & 5.5 & 2.96 & 5.82 & $<0.0001$ & HKDC1 & Hexokinase domain containing 1 \\
\hline 16748304 & 6.07 & 3.54 & 5.78 & 0.0002 & GABARAPL1 & GABA(A) receptor-associated protein like 1 \\
\hline 16772172 & 6.22 & 3.71 & 5.69 & 0.0006 & RPS27A & Ubiquitin C; ribosomal protein S27a \\
\hline 17050328 & 6.4 & 3.9 & 5.65 & 0.0003 & DNAJB9 & DnaJ (Hsp40) homolog, subfamily B, member 9 \\
\hline 16927633 & 6.45 & 3.98 & 5.55 & 0.0002 & SDF2L1 & Stromal cell-derived factor 2 -like 1 \\
\hline 16859795 & 6.87 & 4.43 & 5.45 & $<0.0001$ & GDF15 & Growth differentiation factor 15 \\
\hline 16700911 & 4.51 & 2.09 & 5.35 & 0.0001 & ERO1B & Endoplasmic reticulum oxidoreductase beta \\
\hline 17024448 & 8.06 & 5.66 & 5.25 & 0.0008 & FBXO30 & F-box protein 30 \\
\hline 16756209 & 4.83 & 2.45 & 5.2 & 0.0003 & LOC105369949 & Uncharacterized LOC105369949 \\
\hline 16871000 & 5.49 & 3.12 & 5.16 & $<0.0001$ & LINC00662 & Long intergenic non-protein coding RNA 662 \\
\hline 16800301 & 5.69 & 3.38 & 4.95 & 0.0002 & PDIA3 & Protein disulfide isomerase family A member 3 \\
\hline 16984032 & 6.33 & 7.85 & -2.85 & 0.0002 & SKP2 & S-phase kinase-associated protein 2, E3 ubiquitin protein ligase \\
\hline 16677071 & 4.39 & 5.9 & -2.86 & 0.0006 & SERTAD4 & SERTA domain containing 4 \\
\hline 17075529 & 3.58 & 5.12 & -2.91 & 0.0011 & ENTPD4 & Ectonucleoside triphosphate diphosphohydrolase 4 \\
\hline 16725041 & 6.74 & 8.29 & -2.92 & 0.0031 & FAM111B & Family with sequence similarity 111 , member B \\
\hline 16887840 & 3.79 & 5.37 & -2.99 & 0.0004 & CDCA7 & Cell division cycle associated 7 \\
\hline 17003249 & 3.01 & 4.6 & -3 & 0.0001 & PRR7-AS1 & PRR7 antisense RNA 1 \\
\hline 16696533 & 5.04 & 6.63 & -3.03 & 0.0052 & SNORD75 & Small nucleolar RNA, C/D box 75 \\
\hline 16970435 & 3.09 & 4.7 & -3.04 & 0.0006 & SPRY1 & Sprouty RTK signaling antagonist 1 \\
\hline 16906615 & 3.76 & 5.37 & -3.05 & 0.0003 & SDPR & Serum deprivation response \\
\hline 16837061 & 5.42 & 7.03 & -3.05 & 0.0026 & SNORD104 & Small nucleolar RNA, C/D box 104 \\
\hline 16844356 & 4.78 & 6.42 & -3.13 & 0.0001 & TNS4 & tensin 4 \\
\hline 16733516 & 3.75 & 5.57 & -3.52 & 0.0003 & ADAMTS 15 & ADAM metallopeptidase with thrombospondin type 1 motif 15 \\
\hline 16925023 & 3.28 & 5.31 & -4.07 & 0.0011 & SNORA80A & Small nucleolar RNA, H/ACA box 80A \\
\hline 17004903 & 3.47 & 5.81 & -5.06 & 0.0010 & EDN1 & Endothelin 1 \\
\hline 16912362 & 4.56 & 7.27 & -6.56 & 0.0001 & ID1 & $\begin{array}{l}\text { Inhibitor of DNA binding 1, dominant } \\
\text { Negative helix-loop-helix protein }\end{array}$ \\
\hline
\end{tabular}

further understanding of the pro-survival/pro-death ER/UPR processes and the relevance timing on cancer initiation, progression and treatment (48). It is believed that if we can further understand control of ER stress regulators on cancer growth, we can successfully use this information to overcome acquired resistance to (49) and augment existing 


\section{3-O-Acetyl- $\beta$-boswellic acid}

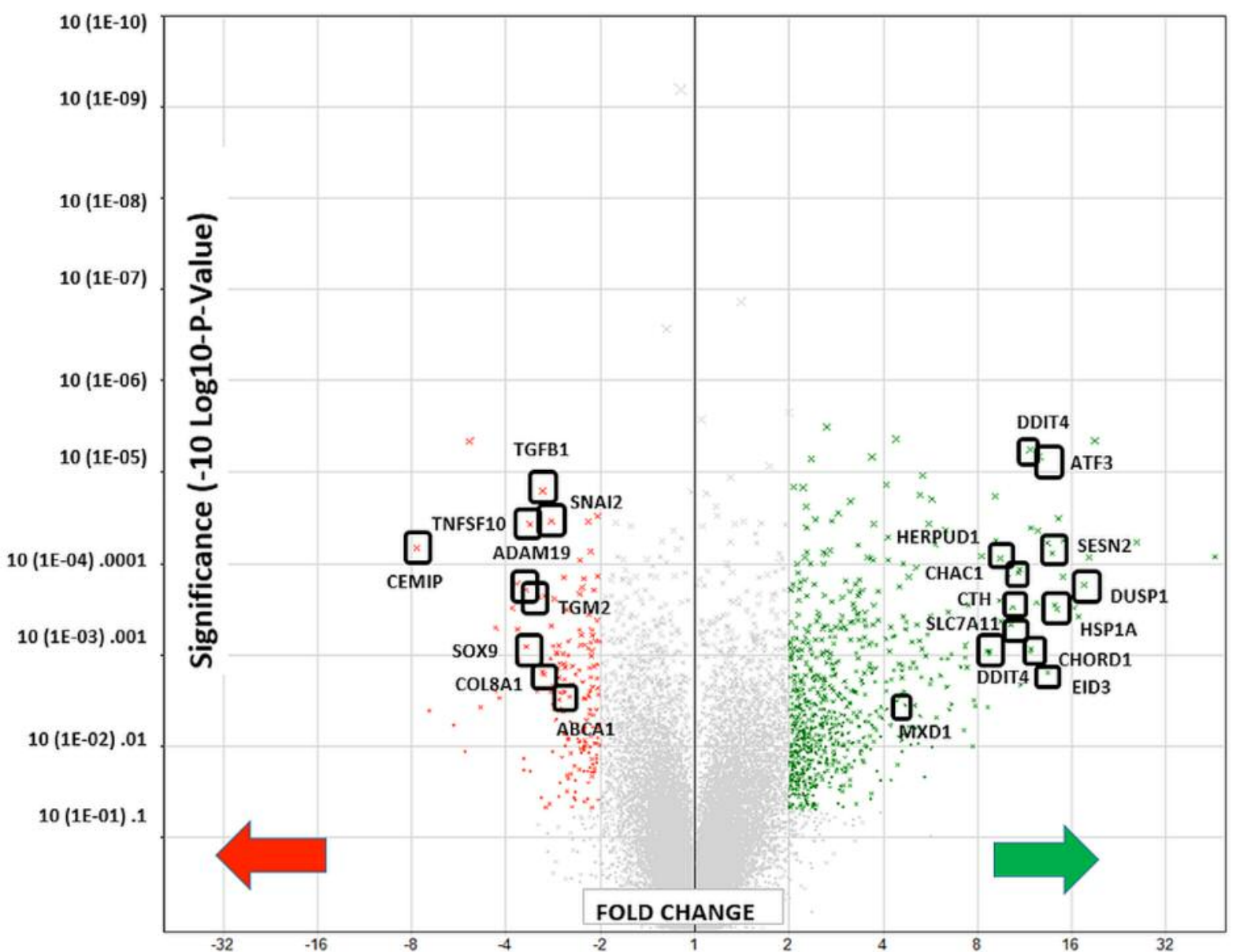

Figure 6. WT changes in 3-OAßBA treated cells using GeneChip ${ }^{T M}$ Human Gene 2.1 ST Array. 48226 transcripts tested: 931 DEGs were identified (391 up-regulated/540 down-regulated). The data are presented as a volcano Plot (fold change by significance) for whole transcriptome changes in 3-OA $\beta B A$ treated MDA-MB-231 cells vs. controls, $n=3$. The left panel shows down-regulated genes (red)/right panel shows up-regulated genes (green): highlighting some of the top changes, also listed in Table II.

Table II. Largest differential shifts incurred by 3-OABBA in MDA-MB-231 cells. The data represent signal, fold-change, p-value, gene symbol and gene description. Top mRNA Changes: Affymetrix Microarray WT Human 2.1 ST.

\begin{tabular}{lcccccc}
\hline Transcript & 3-OAßBA & Control & Fold & ANOVA & Gene & Gene \\
\hline Cluster ID & $\begin{array}{c}\text { Bi-weighted } \\
\text { AVE Signal } \\
\text { Log2 }\end{array}$ & $\begin{array}{c}\text { Bi-weighted } \\
\text { AVE Signal } \\
\text { Log2 }\end{array}$ & Change & $p$-Value & Symbol & Description \\
\hline 17016375 & 7.32 & 2.47 & 28.77 & 0.0001 & HIST1H1T & Histone cluster 1, H1t \\
17114701 & 7.12 & 2.54 & 23.91 & 0.0038 & CDR1 & Cerebellar degeneration related protein 1 \\
17083614 & 7.71 & 3.91 & 13.9 & 0.0002 & LURAP1L & Leucine rich adaptor protein 1-like \\
17005573 & 8.39 & 4.6 & 13.88 & 0.0002 & HIST1H2BD & Histone cluster 1, H2bd \\
16692603 & 7.32 & 3.53 & 13.77 & 0.0001 & HIST2H2BF & Histone cluster 2, H2bf \\
17016379 & 7.07 & 3.35 & 13.17 & 0.0005 & HIST1H2BC & Histone cluster 1, H2bc \\
\hline
\end{tabular}


Table II. Continued

\begin{tabular}{|c|c|c|c|c|c|c|}
\hline Transcript & $3-\mathrm{OA} \beta \mathrm{BA}$ & Control & Fold & ANOVA & Gene & Gene \\
\hline Cluster ID & $\begin{array}{l}\text { Bi-weighted } \\
\text { AVE Signal } \\
\text { Log2 }\end{array}$ & $\begin{array}{l}\text { Bi-weighted } \\
\text { AVE Signal } \\
\text { Log2 }\end{array}$ & Change & $p$-Value & Symbol & Description \\
\hline 16756310 & 8.34 & 4.75 & 12.02 & 0.0001 & TCP11L2 & t-complex 11 , testis-specific-like 2 \\
\hline 16691619 & 7.17 & 3.68 & 11.22 & 0.0006 & LINC00622 & Long intergenic non-protein coding RNA 622 \\
\hline 16677278 & 7.12 & 3.78 & 10.17 & 0.0001 & ATF3 & Activating transcription factor 3 \\
\hline 16756202 & 9.71 & 6.41 & 9.8 & 0.0002 & EID3 & EP300 interacting inhibitor of differentiation 3 \\
\hline 16692611 & 6.16 & 2.88 & 9.73 & 0.0001 & HIST2H2BF & Histone cluster $2, \mathrm{H} 2 \mathrm{bf}$ \\
\hline 17006863 & 11.42 & 8.15 & 9.63 & 0.0001 & HSPA1B,A & Heat shock $70 \mathrm{kDa}$ protein $1 \mathrm{~A} ; \mathrm{b}$ \\
\hline 17002846 & 9.7 & 6.45 & 9.52 & 0.0001 & DUSP1 & Dual specificity phosphatase 1 \\
\hline 16697370 & 7.02 & 3.81 & 9.29 & 0.0004 & PTGS2 & Prostaglandin-endoperoxide synthase 2 \\
\hline 17052552 & 5.88 & 2.79 & 8.48 & 0.0065 & MGAM2 & Maltase-glucoamylase 2 (putative) \\
\hline 16877555 & 8.5 & 5.49 & 8.09 & 0.0002 & RHOB & Ras homolog family member B \\
\hline 16979917 & 10.69 & 7.69 & 8 & $<0.0001$ & SLC7A11 & Solute carrier family 7 member 11 \\
\hline 16819325 & 9.36 & 6.37 & 7.96 & 0.0001 & HERPUD1 & Homocysteine-inducible, ER stress-inducible, ubi DM 1 \\
\hline 17006881 & 11.44 & 8.48 & 7.78 & $<0.0001$ & HSPA1B,A & Heat shock $70 \mathrm{kDa}$ protein $1 \mathrm{~B} ; \mathrm{A}$ \\
\hline 16670377 & 8.79 & 5.85 & 7.7 & 0.0007 & HIST2H4aB & Histone cluster $2, \mathrm{H} 4 \mathrm{~b}$; histone cluster $2, \mathrm{H} 4 \mathrm{a}$ \\
\hline 16661544 & 7.71 & 4.78 & 7.64 & 0.0011 & SESN2 & Sestrin 2 \\
\hline 16666055 & 7.84 & 4.93 & 7.48 & 0.0003 & $\mathrm{CTH}$ & Cystathionine gamma-lyase \\
\hline 16960801 & 7.61 & 4.73 & 7.37 & 0.0090 & PA2G4P4 & Proliferation-associated $2 \mathrm{G} 4$ pseudogene 4 \\
\hline 17005862 & 5.04 & 2.17 & 7.28 & 0.0055 & HIST1H3H & Histone cluster $1, \mathrm{H} 3 \mathrm{~h}$ \\
\hline 16743222 & 9.02 & 6.19 & 7.14 & 0.0001 & CHORDC1 & Cysteine and histidine rich domain containing 1 \\
\hline 17052425 & 6.04 & 3.23 & 7.04 & 0.0020 & MGAM & Maltase-glucoamylase \\
\hline 16888979 & 8.71 & 5.9 & 7.01 & 0.0009 & NABP1 & Nucleic acid binding protein 1 \\
\hline 16705961 & 9.29 & 6.49 & 6.94 & 0.0002 & DDIT4 & DNA damage inducible transcript 4 \\
\hline 16768738 & 8.84 & 6.05 & 6.92 & $<0.0001$ & NTN4 & Netrin 4 \\
\hline 16924602 & 7.28 & 4.52 & 6.75 & 0.0046 & ADAMTS1 & ADAM metallopeptidase / thrombospondin type $1 \mathrm{M} 1$ \\
\hline 16766578 & 6.17 & 3.47 & 6.51 & 0.0017 & DDIT3 & DNA-damage-inducible transcript 3 \\
\hline 16967771 & 5.61 & 2.96 & 6.25 & 0.0014 & CXCL8 & Chemokine (C-X-C motif) ligand 8 \\
\hline 16992467 & 6.59 & 3.97 & 6.13 & 0.0004 & CREBRF & CREB3 regulatory factor \\
\hline 17050328 & 7.29 & 4.7 & 6.03 & 0.0003 & DNAJB9 & DnaJ (Hsp40) homolog, subfamily B, member 9 \\
\hline 16761631 & 6.95 & 4.46 & 5.6 & 0.0051 & DUSP16 & Dual specificity phosphatase 16 \\
\hline 17061430 & 7.94 & 5.49 & 5.46 & 0.0016 & LINC01004 & Long intergenic non-protein coding RNA 1004 \\
\hline 17088116 & 5.42 & 3 & 5.36 & 0.0061 & MIR4668 & MicroRNA 4668 \\
\hline 16703242 & 6.98 & 4.6 & 5.2 & 0.0005 & OTUD1 & OTU deubiquitinase 1 \\
\hline 17000518 & 6.13 & 3.76 & 5.14 & 0.0016 & HSPA9 & Heat shock 70kDa protein 9 (mortalin) \\
\hline 16903897 & 6.39 & 4.05 & 5.06 & $<0.0001$ & NR4A2 & Nuclear receptor subfamily 4 , group A, member 2 \\
\hline 16799739 & 7.08 & 4.81 & 4.82 & 0.0019 & CHAC1 & ChaC glutathione-specific gamma-glutamylcyclotransferase 1 \\
\hline 17060061 & 7.9 & 5.65 & 4.75 & 0.0005 & ASNS & Asparagine synthetase (glutamine-hydrolyzing) \\
\hline 16692632 & 7.89 & 5.65 & 4.72 & 0.0001 & HIST2H2BE & Histone cluster $2, \mathrm{H} 2 \mathrm{be}$ \\
\hline 16869653 & 10.54 & 8.3 & 4.71 & $<0.0001$ & DNAJB1 & DnaJ (Hsp40) homolog, subfamily B, member 1 \\
\hline 16951188 & 5.66 & 3.44 & 4.66 & 0.0018 & METTL6 & Methyltransferase like 6 \\
\hline 16743432 & 5.34 & 3.31 & 4.08 & 0.0018 & SESN3 & Sestrin 3 \\
\hline 16859763 & 5.88 & 7.73 & -3.62 & 0.0068 & IFI30 & Interferon, gamma-inducible protein 30 \\
\hline 17075529 & 3.81 & 5.67 & -3.64 & 0.0002 & ENTPD4 & Ectonucleoside triphosphate diphosphohydrolase 4 \\
\hline 16845657 & 8.02 & 9.88 & -3.64 & 0.0077 & SLC25A39 & Solute carrier family 25, member 39 \\
\hline 17000208 & 3.79 & 5.69 & -3.73 & 0.0023 & VTRNA2-1 & Vault RNA 2-1 \\
\hline 16815310 & 7.86 & 9.79 & -3.8 & 0.0368 & TNFRSF12A & Tumor necrosis factor receptor superfamily, member $12 \mathrm{~A}$ \\
\hline 16925398 & 5.3 & 7.23 & -3.81 & 0.0064 & RUNX1-IT1 & RUNX1 intronic transcript 1 \\
\hline 16866946 & 7.43 & 9.37 & -3.83 & 0.0465 & TIMM13 & Translocase of inner mitochondrial mem 13 homolog (yeast) \\
\hline 16920671 & 4.86 & 6.81 & -3.87 & 0.0039 & PMEPA1 & Prostate transmembrane protein, androgen induced 1 \\
\hline 16921433 & 4.76 & 6.71 & -3.87 & 0.0049 & RGS19 & Regulator of G-protein signaling 19 \\
\hline 16837418 & 7.05 & 9.07 & -4.06 & 0.0048 & SOX9 & SRY box 9 \\
\hline 16726183 & 8.29 & 10.33 & -4.09 & 0.0175 & COX8A & Cytochrome c oxidase subunit VIIIA (ubiquitous) \\
\hline 16811638 & 5.65 & 7.75 & -4.29 & 0.0047 & SEMA7A & Semaphorin 7A, GPI membrane anchor \\
\hline 16828886 & 4.26 & 6.42 & -4.45 & 0.0160 & GINS2 & GINS complex subunit 2 (Psf2 homolog) \\
\hline 16919158 & 5.91 & 8.22 & -4.96 & 0.0032 & TGM2 & Transglutaminase 2 \\
\hline 16819233 & 4.56 & 6.92 & -5.12 & 0.0066 & MT1A & Metallothionein 1A \\
\hline 16803754 & 4.95 & 7.8 & -7.22 & 0.0015 & CEMIP & Cell migration inducing protein, hyaluronan binding \\
\hline
\end{tabular}




\section{Boswellia Seratta Extract}
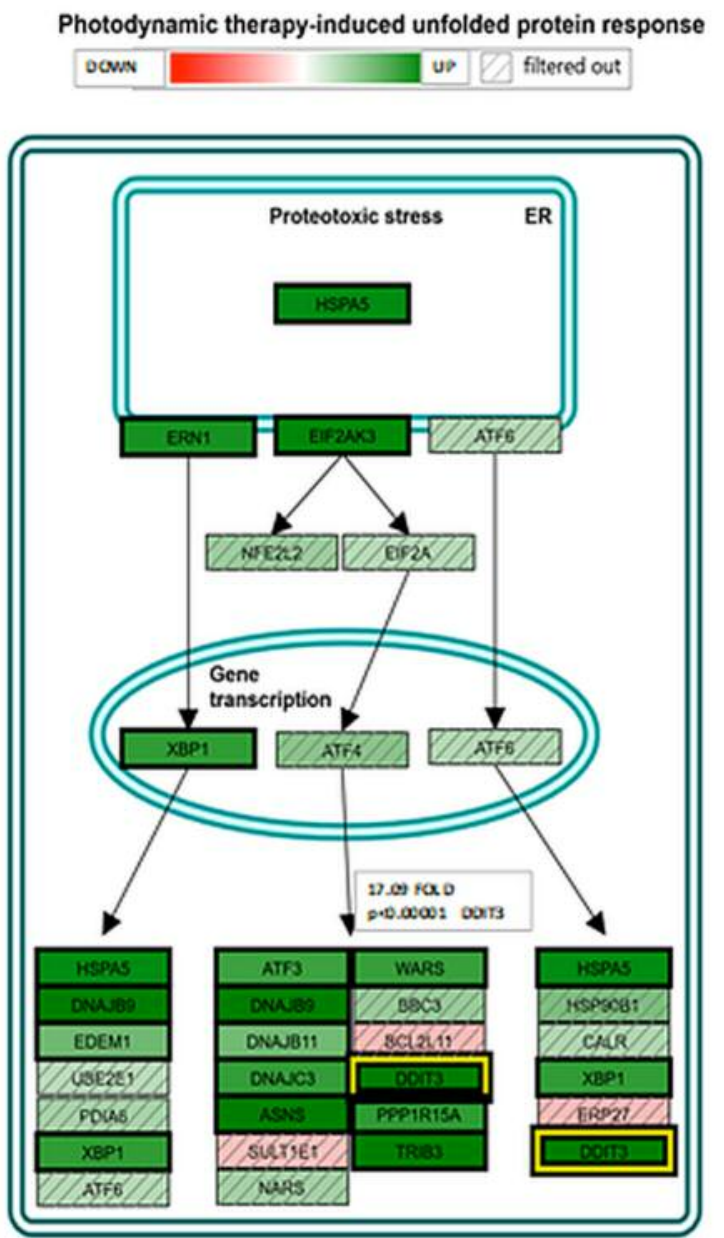

\section{3-O-Acetyl-6-boswellic acid}
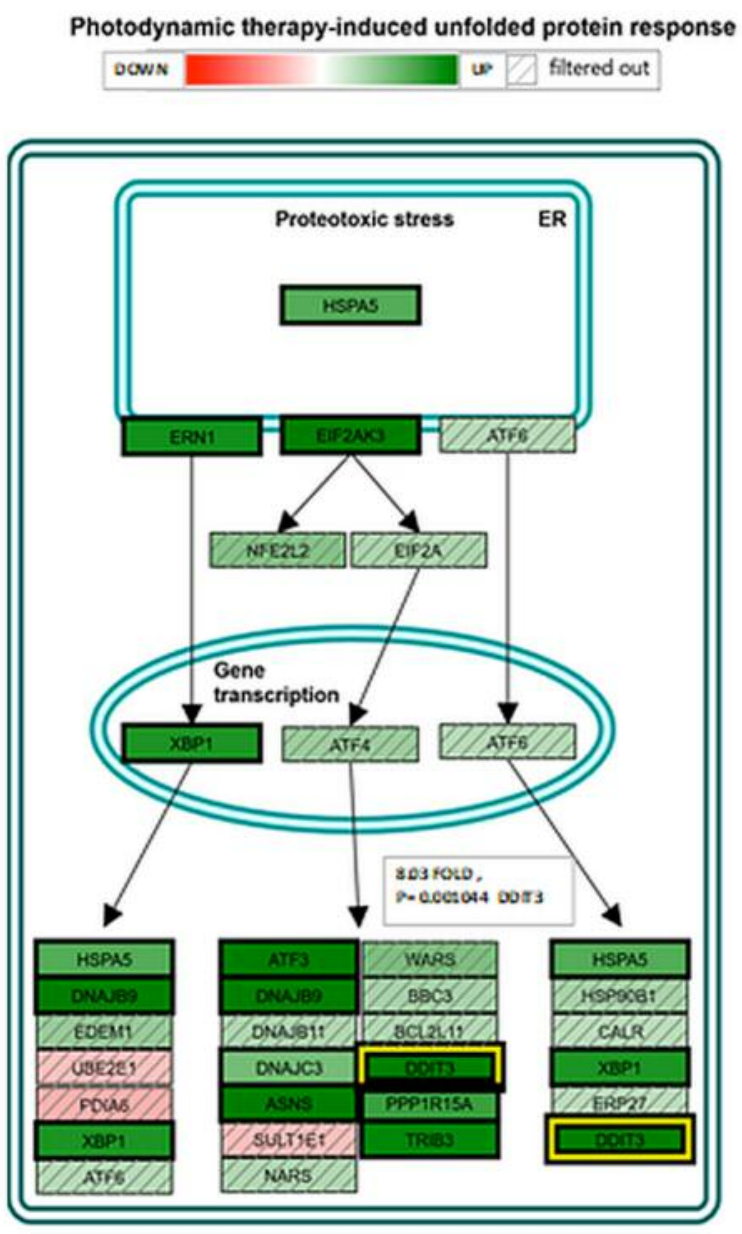

Figure 7. Affymetrix Transcription Analysis Console/Wikipaths Correlation by Significance shows impact on Photodynamic therapy unfolded protein response by BSE and 3-3-OA $\beta B A$ in MDA-MB-231 cells, with a high degree of overlap. The data represents relative fold change by intensity (green) up-regulation, (red) down-regulation with (IIIII) filtered out as non-significant directional changes. Highlighted in yellow is the shift in DDIT3, with values presented.

cancer therapies (50). The data from this study show BSE and $3-\mathrm{OA} \beta \mathrm{BA}$ to impact several processes within the ER/UPR.

$E R / U P R$. If we take a look at the normal function of the ER under non-stress conditions, its main purpose is in the posttranslational modification and folding of mature proteins using chaperones and foldases, which are then trafficked to the Golgi. Anything that impairs this system elicits ER stress and a UPR. This later response (ER/UPR) serves a primary means to reduce protein load by decreasing translation, and removing mis-folded proteins. This is accomplished by increasing the folding capability of the ER, and the degradation rate of damaged proteins through binding to glucose-regulated protein 78 (Bip/GRP78) (a pivotal event) in preparation for disposal through an endoplasmic reticulum-associated degradation pathway (ERAD) by the ubiquitin/proteasome pathway or alternatively, an autophagic/lysosomal pathway $(51,52)$.

Briefly, the ER/UPR main branches can all initiate proapoptotic events. These include:

[Pathway 1] protein kinase RNA-like endoplasmic reticulum kinase (PERK),

[Pathway 2] inositol-requiring enzyme-1 (IRE1), or

[Pathway 3] activating transcription factor-6 (ATF-6) $(53,54)$.

The effects of 3-OA $\beta \mathrm{BA}$ and BSE on the transcriptome suggests extensive up-regulation on many of these processes. 


\section{Boswellia Seratta Extract}

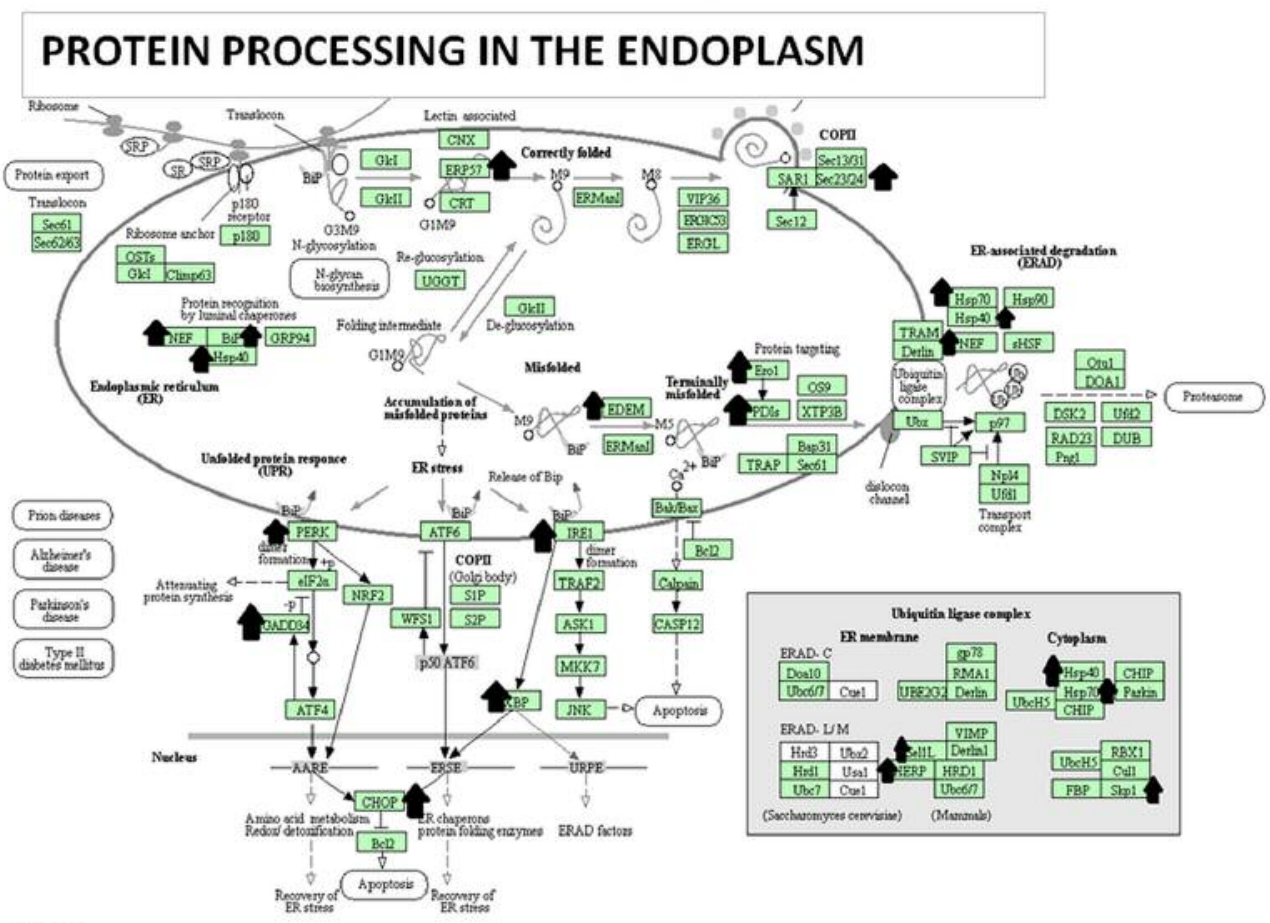

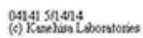

\section{3-O-Acetyl-6-boswellic acid}

\section{PROTEIN PROCESSING IN THE ENDOPLASM}

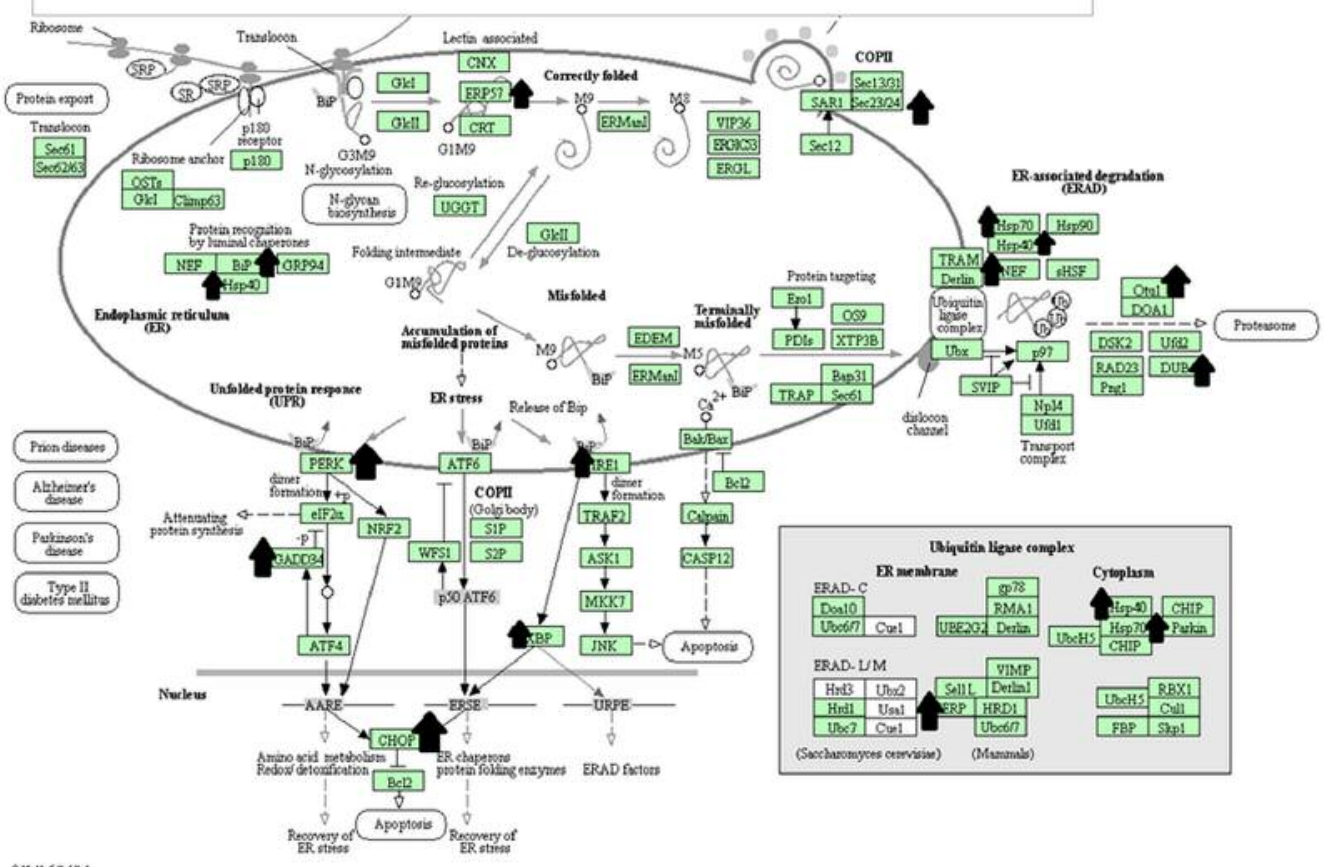

(a) 6

Figure 8. DAVID Functional Annotation Bioinformatics Microarray Analysis. DAVID Bioinformatics Resources 6.8. KEGG Diagram Overlap of up-regulated transcripts in response by BSE and 3-O-Acetyl- $\beta$-boswellic acid in MDA-MB-231 cells, with a high degree of overlap. The data represents Protein Processing in the ER and up-regulated transcripts noted by an arrow. 
Table III. Biological processes impacted by BSE-treated MDA-MB-231 cells. The data are derived from full dataset analysis using a relational database provided by geneontology.org. This service connects GO Enrichment Analysis to the analysis tool from the PANTHER Classification System, which is maintained up to date with GO annotations. The p-Value (Column 4) is the probability of seeing at least $x$ number of genes (Column 2) out of the total $n$ genes in the process annotated (Column 1) with greater fold enrichment score (Column 3) corresponding to relevant pathway significance impact.

Table IIIa: GO biological process: Up-regulated by BSE

\begin{tabular}{|c|c|c|c|}
\hline $\begin{array}{l}\text { Homo sapiens - } \\
\text { REFLIST (21002) }\end{array}$ & Genes & $\begin{array}{l}\text { (fold } \\
\text { Enrichment) }\end{array}$ & ( $p$-Value) \\
\hline 12 & 6 & 44.31 & 0.0001 \\
\hline 12 & 5 & 36.92 & 0.0028 \\
\hline 31 & 8 & 22.87 & $<0.0001$ \\
\hline 25 & 6 & 21.27 & 0.0045 \\
\hline 58 & 12 & 18.33 & $<0.0001$ \\
\hline 36 & 7 & 17.23 & 0.0020 \\
\hline 115 & 21 & 16.18 & $<0.0001$ \\
\hline 160 & 29 & 16.06 & $<0.0001$ \\
\hline 121 & 21 & 15.38 & $<0.0001$ \\
\hline 180 & 30 & 14.77 & $<0.0001$ \\
\hline 36 & 6 & 14.77 & 0.0359 \\
\hline 42 & 7 & 14.77 & 0.0056 \\
\hline 37 & 6 & 14.37 & 0.0419 \\
\hline 139 & 22 & 14.03 & $<0.0001$ \\
\hline 75 & 11 & 13 & $<0.0001$ \\
\hline 244 & 32 & 11.62 & $<0.0001$ \\
\hline 115 & 13 & 10.02 & $<0.0001$ \\
\hline 73 & 8 & 9.71 & 0.0198 \\
\hline 121 & 13 & 9.52 & $<0.0001$ \\
\hline 156 & 12 & 6.82 & 0.0026 \\
\hline 237 & 16 & 5.98 & 0.0002 \\
\hline 173 & 11 & 5.63 & 0.0487 \\
\hline 215 & 13 & 5.36 & 0.0119 \\
\hline 208 & 12 & 5.11 & 0.0486 \\
\hline 281 & 16 & 5.05 & 0.0016 \\
\hline 383 & 20 & 4.63 & 0.0002 \\
\hline 313 & 16 & 4.53 & 0.0065 \\
\hline 294 & 15 & 4.52 & 0.0147 \\
\hline
\end{tabular}

PERK-mediated unfolded protein response

Positive regulation of transcription from RNA polymerase

II promoter in response to ER stress

Intrinsic apoptotic signaling pathway in response to endoplasmic reticulum stress

Positive regulation of transcription from RNA polymerase

II promoter in response to stress

IRE1-mediated unfolded protein response

ER-nucleus signaling pathway

Endoplasmic reticulum unfolded protein response

Response to unfolded protein

Cellular response to unfolded protein

Response to topologically incorrect protein

Positive regulation of response to endoplasmic reticulum stress

Serine family amino acid metabolic process

Cellular response to glucose starvation

Cellular response to topologically incorrect protein

Regulation of response to endoplasmic reticulum stress

Response to endoplasmic reticulum stress

Regulation of transcription from RNA polymerase II promoter in response to stress

Cell redox homeostasis

Regulation of DNA-templated transcription in response to stress

Intrinsic apoptotic signaling pathway

Protein folding

Response to starvation

Response to toxic substance

Cellular response to extracellular stimulus

Cellular response to external stimulus

Regulation of apoptotic signaling pathway

Cellular amino acid metabolic process

Apoptotic signaling pathway

Analysis Type: http://www.geneontology.org/PANTHER Overrepresentation Test (release 20170413)

Annotation Version and Release Date:GO Ontology database Released 2017-07-1

Analyzed List: Up-regulated by BSE in MDA-231 Cells

Reference List: Homo sapiens (all genes in database)

\begin{tabular}{lrrr}
\hline Table IIIb: GO biological process: Down-regulated by BSE & $\begin{array}{c}\text { Homo sapiens - } \\
\text { REFLIST (21002) }\end{array}$ & GENES & $\begin{array}{c}\text { (fold } \\
\text { Enrichment) }\end{array}$ \\
\hline Negative regulation of epithelial cell differentiation & 39 & 4 & 44.88 \\
Mesenchymal cell differentiation & 132 & 6 & 0.019 \\
Regulation of ossification & 183 & 6 & 19.89 \\
Mesenchyme development & 194 & 6.005 \\
Animal organ morphogenesis & 880 & 11 & 0.034 \\
\hline
\end{tabular}

Pathway 1/PERK: Briefly, when proteins are misfolded in the ER, they bind to BiP/Grp78 which triggers X-box-binding protein 1 (XBP1) splicing, which then initiates PERK to phosphorylate $+\mathrm{P}(\mathrm{eIF} 2 \alpha)$. We found evidence of BSE not only up-regulating XBP1 +3.31, $p=0.0003$ (3-OA $\beta$ BA ), +3.04 , $p=0.0003$ (BSE) but also PERK (EIF2AK3) $+4.6 p=0.0003(3-$ $\mathrm{OA} \beta \mathrm{BA}$ ) and $+3.67, p<0.0003$ (BSE). This active $+\mathrm{PeIF} 2 \alpha$, is central to the control of downstream events which halting protein synthesis, cell cycle arrest in addition to activating ATF4, which in turn elevates ATG12, TRB3 (AKT/mTOR 
Table IV. Biological processes impacted by 3-O-Acetyl- $\beta$-boswellic acid-treated MDA-MB-231 cells. The data are derived from full dataset analysis using a relational database provided by geneontology.org. This service connects GO Enrichment Analysis to the analysis tool from the PANTHER Classification System, which is maintained up to date with GO annotations. The p-Value (Column 4) is the probability of seeing at least $x$ number of genes (Column 2) out of the total $n$ genes in the process annotated (Column 1) with greater fold enrichment score (Column 3 ) corresponding to relevant pathway significance impact.

Table IVa: GO biological process: Up-regulated by 3-OAßBA

$\begin{array}{cc}\text { Homo sapiens - } & \text { Genes } \\ \text { REFLIST (21002) } & \text { Enrichment) }\end{array}$

PERK-mediated unfolded protein response

Positive regulation of transcription from RNA polymerase

II promoter in response to ER stress

Positive regulation of transcription from RNA polymerase

II promoter in response to stress

ER-nucleus signaling pathway

Response to unfolded protein

Positive regulation of smooth muscle cell proliferation

Regulation of response to endoplasmic reticulum stress

Endoplasmic reticulum unfolded protein response

Response to topologically incorrect protein

Cellular response to unfolded protein

Cellular response to topologically incorrect protein

Regulation of smooth muscle cell proliferation

Regulation of transcription from RNA polymerase

II promoter in response to stress

Cellular response to starvation

Regulation of DNA-templated transcription in response to stress

Regulation of fat cell differentiation

Nucleosome assembly

Response to hydrogen peroxide

Cellular response to nutrient levels

Response to starvation

Cellular response to extracellular stimulus

Chromatin assembly

Response to endoplasmic reticulum stress

Nucleosome organization

Cellular response to external stimulus

Chromatin assembly or disassembly

Response to reactive oxygen species

\begin{tabular}{rrrr}
12 & 7 & 46.06 & $<0.0001$ \\
12 & 5 & 32.9 & 0.0049 \\
25 & & & \\
36 & 7 & 22.11 & 0.0004 \\
60 & 8 & 17.55 & 0.0002 \\
74 & 23 & 11.35 & $<0.0001$ \\
75 & 10 & 10.67 & 0.0005 \\
15 & 10 & 10.53 & 0.0005 \\
80 & 15 & 10.3 & $<0.0001$ \\
21 & 23 & 10.09 & $<0.0001$ \\
39 & 15 & 9.79 & $<0.0001$ \\
15 & 15 & 8.52 & $<0.0001$ \\
& 12 & 8.24 & 0.0004 \\
15 & & & \\
36 & 12 & 8.24 & 0.0004 \\
21 & 14 & 8.13 & $<0.0001$ \\
13 & 12 & 7.83 & 0.0006 \\
18 & 11 & 7.69 & 0.0026 \\
188 & 11 & 7.36 & 0.0039 \\
80 & 10 & 7.31 & 0.0139 \\
13 & 16 & 7.02 & $<0.0001$ \\
08 & 15 & 6.85 & 0.0001 \\
34 & 18 & 6.83 & $<0.0001$ \\
44 & 11 & 6.48 & 0.0133 \\
47 & 19 & 6.15 & $<0.0001$ \\
81 & 11 & 5.91 & 0.0319 \\
54 & 21 & 5.9 & $<0.0001$ \\
83 & 11 & 5.64 & 0.0492 \\
& 12 & 5.18 & 0.0437 \\
\hline & & &
\end{tabular}

Analysis Type: http://www.geneontology.org/PANTHER Overrepresentation Test (release 20170413)

Annotation Version and Release Date: GO Ontology database Released 2017-07-21

Analyzed List: Up-regulated by 3-OAßBA in MDA-231 Cells

Reference List: Homo sapiens (all genes in database)

Table IVb: GO biological process: Down-regulated by 3-OA $\beta$ BA

Homo sapiens -
REFLIST (21002)

GENES

(fold

Enrichment)

( $p$-Value)

Intrinsic apoptotic signaling pathway in response to DNA damage

Positive regulation of apoptotic signaling pathway

Extracellular matrix organization

Extracellular structure organization

Response to oxidative stress

Regulation of endopeptidase activity

Regulation of apoptotic signaling pathway

Regulation of peptidase activity

Negative regulation of protein metabolic process

Negative regulation of cellular protein metabolic process

Negative regulation of molecular function

Regulation of cellular component organization

\begin{tabular}{rlll}
70 & 11 & 6.85 & 0.008 \\
181 & 17 & 4.09 & 0.014 \\
308 & 22 & 3.11 & 0.036 \\
309 & 22 & 3.1 & 0.038 \\
366 & 25 & 2.98 & 0.018 \\
391 & 26 & 2.9 & 0.018 \\
383 & 25 & 2.84 & 0.038 \\
418 & 27 & 2.81 & 0.019 \\
1105 & 55 & 2.17 & 0.001 \\
1046 & 51 & 2.12 & 0.004 \\
1161 & 55 & 2.06 & 0.004 \\
2331 & 87 & 1.63 & 0.035 \\
\hline
\end{tabular}


Table V. Transcriptome miRNA changes in BSE treated MDA-MB-231 cells. The data represents cluster, signal, fold change, p-value, gene symbol, and gene targets.

\begin{tabular}{llllll}
\hline miRNA Changes: Affymetrix & 4.1 mRNA Array & & & & \\
\hline Transcript & BSE & Control & Fold & ANOVA & Gene \\
\hline Cluster ID & Bi-weighted AVE Signal Log2 & Bi-weighted AVE Signal Log3 & Change & $p$-Value & Symbol \\
\hline 20519591 & 2.11 & 1.09 & 2.03 & 0.00398 & hsa-miR-4740-3p \\
20518919 & 5.7 & 6.92 & -2.34 & 0.004005 & hsa-miR-4521 \\
20500722 & 3.85 & 5.3 & -2.72 & 0.009182 & hsa-miR-27b-5p \\
20501169 & 0.7 & 2.2 & -2.82 & 0.020278 & hsa-miR-34b-3p \\
20500786 & 0.96 & 2.28 & -2.49 & 0.032848 & hsa-miR-184 \\
20538228 & 4.1 & 2.95 & 2.22 & 0.039779 & U70D \\
\hline
\end{tabular}

inhibitor), triggering autophagy required for removal of unfolded proteins. These events are often simultaneous with the rise in $\mathrm{C} / \mathrm{EBP}$ homologous protein transcription factor (CHOP)/DNA damage-inducible transcript 3, 4 or GADD153,GADD34, and ATF3 (triggering cell death) $(55,56)$. The data in this study show mediated effects for TRB3 [+6.3 fold, $p<0.0001 \mathrm{BSE} /+3.68, p<0.00013$-OA $\beta \mathrm{BA}]$ ATF3 [+12.61 fold, $p<0.0001 \mathrm{BSE} /+2.9, p<0.00013-\mathrm{OA} \beta \mathrm{BA}]$, DDIT3 [+17.09 fold, $p<0.0001 \mathrm{BSE} /+8.03, p<0.00013-$ OA $\beta \mathrm{BA}]$ and DDIT4 $[+8.41$ fold, $p<0.0001 \mathrm{BSE} /+11.77$, $p<0.00013-\mathrm{OA} \beta \mathrm{BA}]$. If CHOP driven ER stress mediated apoptosis prevails, this would drive up-regulation of death molecules (BIM, BAX, PUMA), death receptors (Tnfrsf10b/Dr5) juxtaposed to a reduction of BLC2 (antiapoptotic molecules) (55, 57), activation of JNK and p38MAPK, rise in immediate early response genes (EGR-1), and ASK1 recruitment to IRE1-TRAF2, linking pathway 1 to the next ER/UPR stress pathway Pathway 2/ IRE1 $\alpha$; ERN1. The data in this study again, show consistent trends in downstream events including elevated levels of EGR-1, [+ 15.18 fold, $p<0.0001 \mathrm{BSE} /+2.48, p<0.00013$-OA $\beta \mathrm{BA}]$, TRB3 [+6.3 fold, $p<0.0001 \mathrm{BSE} /+3.68, p<0.00013-\mathrm{OA} \beta \mathrm{BA}]$ and ATF3 [+12.61 fold, $p<0.0001 \mathrm{BSE} /+2.9, p<0.00013-\mathrm{OA} \beta \mathrm{BA}]$.

Pathway 2/ IRE1 $\alpha$; ERN1: In response to unfolded proteins, IRE1 $\alpha$; ERN1 is cleaved by endoribonuclease activity at the 26bp intron of XBP1 (involved with pathway 1 above), which then facilitates the formation of transcription factor XBP1 mRNA, where IRE1-XBP1 can trigger recruitment of TRAF2 to the ER membrane (+ASK1 recruitment). TRAF2 is an activator of apoptosis signalregulating kinase 1 (ASK1), which can lead to JNK mediated apoptosis. Also, this pathway can trigger ERO1 $\alpha$ to activate the ER calcium channel inositol-1,4,5-trisphosphate receptor 1 (IP3R1) enabling activate cAMP response elements (CREs).

Pathway 3/ATF 6: Upon ER stress, ATF6 dissociates from GRP78/BiP - leaving it free to translocate to the Golgi, where it is cleaved by S1P and S2P, and its fragment released

\begin{tabular}{ll}
\hline Gene targets & \\
\hline$[\mathrm{miR}-34 \mathrm{~b}-3 \mathrm{p}]$ & {$[\mathrm{miR}-184]$} \\
\hline$M E T$ & INPPL1 \\
CREB & NFAT1 \\
CDK4 & AK T2 \\
$c-M Y C$ & NFATC2 \\
BCL2 & \\
$C D K 6$ & \\
$M Y C$ & \\
VEGFA & \\
\hline
\end{tabular}

to the cytosol. ATF6 fragments can include the active $50 \mathrm{kDa}$ transcription factor (ATF6 p50) which translocate to the nucleus. There, ATF6 p50 and XBP1 bind ERSE promoters and up-regulate chaperones that are involved with unfolded protein response including GRP78.

ER/UPR stress mediated apoptosis and cancer drugs. Many natural products are being reported to impact the aforementioned, including a spiked rise in Grp78, CHOP with activated ER/UPR - PCD occurring through PERK, IRE1alpha and ATF6 pathways as in the case of cryptotanshinone (32) 2(3,4-dihydroxyphenyl)ethanol (olive oil) (58) selenium (59) methylseleninic acid, sodium selenite (33) xanthohumol (hops), docosahexaenoic acid $(34,35)$ isochaihulactone (Nan-Chai-Hu) (36) Shikonin (Lithospermum erythrorhizon) (37) chrysin (31) curcumin (40) silibinin (41) or whole herbs such as the Chinese herbal medicine Tu Bei Mu (39). A number of drugs also mediate similar effects, such as steroids, platins, taxol, alkylating agents, or cancer chemicals which on the one hand block the growth of diverse cancers, and on the other hand elevate ER/UPR - PCD, associated with up-regulation of GRP78, CHOP and three UPRassociated pathways, PERK, IRE1alpha, and ATF6 (42-44, 46, 
60). It is also believed that hydrogen peroxide tumor mediated cell death also corresponds to up-regulation of the PERK branch evident by $+\mathrm{P}$ eIF $2 \alpha$ and the mRNA levels of activating transcription factor 4 (ATF4), C/EBP homologous (CHOP) and tribbles homolog 3 (TRB3)(61). The findings in this work, place $3-\mathrm{OA} \beta \mathrm{BA}$ and BSE in this category of anti-cancer agents.

While discussing all the changes in the transcriptome initiated by $3-\mathrm{OA} \beta \mathrm{BA}$ and $\mathrm{BSE}$ are beyond the scope of this paper, noteworthy is the rise in CHAC1, which is involved in the degradation of glutathione $(62,63)$ reported to occur in parallel to rise of ATF4-ATF3-CHOP PERK and the phosphorylation of EIF2 $\alpha$, where its rise creates vulnerability of cancer cells to the losses of glutathione associated with radiation and oxidative insult $(64,65)$ also rendering losses on glutathione detoxification systems (66).

In conclusion, we provide whole transcriptome data analysis of RNA from TNBC cells treated with 3-OA $\beta$ BA and BSE. The data discussed in this publication have been deposited in NCBI's Gene Expression Omnibus and are accessible through GEO Series accession number GSE102891 located at https://www.ncbi.nlm.nih.gov/geo/query/acc.cgi?acc=GSE10 2891.The findings reflect a high probability of ER/UPR involvement through PERK phosphorylation of eIF2 $\alpha$, leading to up-regulation of ATF3, 4, TRB3, DNA damage-inducible transcript 3, 4 (CHOP) and rise in immediate early response genes. Future research will be required to determine the unique controlling factors in common between natural products and the ER/ UPR programmed death events in tumor cells.

\section{Conflicts of Interest}

The Authors wish to confirm that there are no known conflicts of interest associated with this publication and there has been no significant financial support for this work that could have influenced its outcome.

\section{Acknowledgements}

This project was supported by the National Institutes of Health, National Institute on Minority Health and Health Disparities, RCMI grant (8G12MD007582-28.) and COE grant (P20 MD006738).

\section{References}

1 Estrada AC, Syrovets T, Pitterle K, Lunov O, Buchele B, Schimana-Pfeifer J, Schmidt T, Morad SA and Simmet T: Tirucallic acids are novel pleckstrin homology domaindependent Akt inhibitors inducing apoptosis in prostate cancer cells. Mol Pharmacol 77: 378-387, 2010.

2 Yadav VR, Prasad S, Sung B, Gelovani JG, Guha S, Krishnan S and Aggarwal BB: Boswellic acid inhibits growth and metastasis of human colorectal cancer in orthotopic mouse model by downregulating inflammatory, proliferative, invasive and angiogenic biomarkers. Int J Cancer 130: 2176-2184, 2012.

3 Frank MB, Yang Q, Osban J, Azzarello JT, Saban MR, Saban R, Ashley RA, Welter JC, Fung KM and Lin HK: Frankincense oil derived from Boswellia carteri induces tumor cell specific cytotoxicity. BMC Complement Altern Med 9: 6, 2009.

4 Park B, Prasad S, Yadav V, Sung B and Aggarwal BB: Boswellic acid suppresses growth and metastasis of human pancreatic tumors in an orthotopic nude mouse model through modulation of multiple targets. PLoS One 6: e26943, 2011.

5 Ranjbarnejad T, Saidijam M, Moradkhani S and Najafi R: Methanolic extract of Boswellia serrata exhibits anti-cancer activities by targeting microsomal prostaglandin E synthase-1 in human colon cancer cells. Prostaglandins Other Lipid Mediat 131: 1-8, 2017.

6 Dozmorov MG, Yang Q, Wu W, Wren J, Suhail MM, Woolley CL, Young DG, Fung KM and Lin HK: Differential effects of selective frankincense ( $\mathrm{Ru}$ Xiang) essential oil versus nonselective sandalwood (Tan Xiang) essential oil on cultured bladder cancer cells: a microarray and bioinformatics study. Chin Med 9: 18, 2014.

7 Lee DH, Kim SS, Seong S, Woo CR and Han JB: A case of metastatic bladder cancer in both lungs treated with korean medicine therapy alone. Case Rep Oncol 7: 534-540, 2014.

8 Thummuri D, Jeengar MK, Shrivastava S, Areti A, Yerra VG, Yamjala S, Komirishetty P, Naidu VG, Kumar A and Sistla R: Boswellia ovalifoliolata abrogates ROS mediated NF-kappaB activation, causes apoptosis and chemosensitization in Triple Negative Breast Cancer cells. Environ Toxicol Pharmacol 38: 58-70, 2014.

9 Takada Y, Ichikawa H, Badmaev V and Aggarwal BB: Acetyl11-keto-beta-boswellic acid potentiates apoptosis, inhibits invasion, and abolishes osteoclastogenesis by suppressing NFkappa B and NF-kappa B-regulated gene expression. J Immunol 176: 3127-3140, 2006.

10 Zhang YS, Xie JZ, Zhong JL, Li YY, Wang RQ, Qin YZ, Lou HX, Gao ZH and Qu XJ: Acetyl-11-keto-beta-boswellic acid (AKBA) inhibits human gastric carcinoma growth through modulation of the Wnt/beta-catenin signaling pathway. Biochim Biophys Acta 1830: 3604-3615, 2013.

11 Liu JJ, Huang B and Hooi SC: Acetyl-keto-beta-boswellic acid inhibits cellular proliferation through a p21-dependent pathway in colon cancer cells. Br J Pharmacol 148: 1099-1107, 2006.

12 Qurishi Y, Hamid A, Sharma PR, Wani ZA, Mondhe DM, Singh SK, Zargar MA, Andotra SS, Shah BA, Taneja SC and Saxena AK: NF-kappaB down-regulation and PARP cleavage by novel 3-alpha-butyryloxy-beta-boswellic acid results in cancer cell specific apoptosis and in vivo tumor regression. Anticancer Agents Med Chem 13: 777-790, 2013.

13 Kunnumakkara AB, Nair AS, Sung B, Pandey MK and Aggarwal BB: Boswellic acid blocks signal transducers and activators of transcription 3 signaling, proliferation, and survival of multiple myeloma via the protein tyrosine phosphatase SHP1. Mol Cancer Res 7: 118-128, 2009.

14 Chou YC, Suh JH, Wang Y, Pahwa M, Badmaev V, Ho CT and Pan MH: Boswellia serrata resin extract alleviates azoxymethane (AOM)/dextran sodium sulfate (DSS)-induced colon tumorigenesis. Mol Nutr Food Res, 2017. doi: 10.1002/mnfr.201600984. [Epub ahead of print]

15 Xue X, Chen F, Liu A, Sun D, Wu J, Kong F, Luan Y, Qu X and Wang R: Reversal of the multidrug resistance of human ileocecal adenocarcinoma cells by acetyl-11-keto-beta-boswellic acid via down-regulation of P-glycoprotein signals. Biosci Trends 10: 392-399, 2016 
16 Buchele B, Zugmaier W, Estrada A, Genze F, Syrovets T, Paetz C, Schneider B and Simmet T: Characterization of 3alpha-acetyl11-keto-alpha-boswellic acid, a pentacyclic triterpenoid inducing apoptosis in vitro and in vivo. Planta Med 72: 1285-1289, 2006.

17 Mazzio EA and Soliman KF: In vitro screening for the tumoricidal properties of international medicinal herbs. Phytother Res 23: 385-398, 2009.

18 Yazdanpanahi N, Behbahani $\mathrm{M}$ and Yektaeian A: Effect of boswellia thurifera gum methanol extract on cytotoxicity and p53 gene expression in human breast cancer cell line. Iran J Pharm Res 13: 719-724, 2014.

19 Ashburner M, Ball CA, Blake JA, Botstein D, Butler H, Cherry JM, Davis AP, Dolinski K, Dwight SS, Eppig JT, Harris MA, Hill DP, Issel-Tarver L, Kasarskis A, Lewis S, Matese JC, Richardson JE, Ringwald M, Rubin GM and Sherlock G: Gene ontology: tool for the unification of biology. The Gene Ontology Consortium. Nat Genet 25: 25-29, 2000.

20 Huang da W, Sherman BT and Lempicki RA: Systematic and integrative analysis of large gene lists using DAVID bioinformatics resources. Nat Protoc 4: 44-57, 2009.

21 Vlachos IS, Zagganas K, Paraskevopoulou MD, Georgakilas G, Karagkouni D, Vergoulis T, Dalamagas T and Hatzigeorgiou AG: DIANA-miRPath v3.0: deciphering microRNA function with experimental support. Nucleic Acids Res 43: W460-466, 2015.

22 Papadopoulos GL, Alexiou P, Maragkakis M, Reczko M and Hatzigeorgiou AG: DIANA-mirPath: Integrating human and mouse microRNAs in pathways. Bioinformatics 25: 1991-1993, 2009.

23 Zhang Y, Qu X and Jiang L: An oasis in the desert of cancer chemotherapeutic resistance: The enlightenment from reciprocal crosstalk between signaling pathways of UPR and autophagy in cancers. Biomed Pharmacother 92: 972-981, 2017.

24 Papaioannou A and Chevet E: Driving cancer tumorigenesis and metastasis through UPR signaling. Curr Top Microbiol Immunol, 2017. doi: 10.1007/82_2017_36. [Epub ahead of print]

25 Obacz J, Avril T, Le Reste PJ, Urra H, Quillien V, Hetz C and Chevet E: Endoplasmic reticulum proteostasis in glioblastomaFrom molecular mechanisms to therapeutic perspectives. Sci Signal 10: pii: eaal2323, 2017.

26 Koong AC, Chauhan V and Romero-Ramirez L: Targeting XBP-1 as a novel anti-cancer strategy. Cancer Biol Ther 5: 756-759, 2006.

27 Le Mercier M, Lefranc F, Mijatovic T, Debeir O, Haibe-Kains B, Bontempi G, Decaestecker C, Kiss R and Mathieu V: Evidence of galectin-1 involvement in glioma chemoresistance. Toxicol Appl Pharmacol 229: 172-183, 2008.

28 Hsiao JR, Chang KC, Chen CW, Wu SY, Su IJ, Hsu MC, Jin YT, Tsai ST, Takada K and Chang Y: Endoplasmic reticulum stress triggers XBP-1-mediated up-regulation of an EBV oncoprotein in nasopharyngeal carcinoma. Cancer Res 69: 4461-4467, 2009.

29 Salaroglio IC, Panada E, Moiso E, Buondonno I, Provero P, Rubinstein $\mathrm{M}$, Kopecka $\mathrm{J}$ and Riganti $\mathrm{C}$ : PERK induces resistance to cell death elicited by endoplasmic reticulum stress and chemotherapy. Mol Cancer 16: 91, 2017.

30 Corazzari M, Gagliardi M, Fimia GM and Piacentini M: Endoplasmic Reticulum Stress, Unfolded Protein Response, and Cancer Cell Fate. Front Oncol 7: 78, 2017.

31 Ryu S, Lim W, Bazer FW and Song G: Chrysin induces death of prostate cancer cells by inducing ROS and ER stress. J Cell Physiol 232: 3786-3797, 2017.

$32 \mathrm{Wu}$ CF, Seo EJ, Klauck SM and Efferth T: Cryptotanshinone deregulates unfolded protein response and eukaryotic initiation factor signaling in acute lymphoblastic leukemia cells. Phytomedicine 23: 174-180, 2016.

33 Shigemi Z, Manabe K, Hara N, Baba Y, Hosokawa K, Kagawa $\mathrm{H}$, Watanabe $\mathrm{T}$ and Fujimuro $\mathrm{M}$ : Methylseleninic acid and sodium selenite induce severe ER stress and subsequent apoptosis through UPR activation in PEL cells. Chem Biol Interact 266: 28-37, 2017.

34 Jakobsen CH, Storvold GL, Bremseth H, Follestad T, Sand K, Mack M, Olsen KS, Lundemo AG, Iversen JG, Krokan HE and Schonberg SA: DHA induces ER stress and growth arrest in human colon cancer cells: associations with cholesterol and calcium homeostasis. J Lipid Res 49: 2089-2100, 2008.

35 Slagsvold JE, Pettersen CH, Follestad T, Krokan HE and Schonberg SA: The antiproliferative effect of EPA in HL60 cells is mediated by alterations in calcium homeostasis. Lipids 44 : 103-113, 2009.

36 Tsai SF, Tao M, Ho LI, Chiou TW, Lin SZ, Su HL and Harn HJ: Isochaihulactone-induced DDIT3 causes ER stress-PERK independent apoptosis in glioblastoma multiforme cells. Oncotarget 8: 4051-4061, 2017.

37 Piao JL, Cui ZG, Furusawa Y, Ahmed K, Rehman MU, Tabuchi $\mathrm{Y}$, Kadowaki $\mathrm{M}$ and Kondo T: The molecular mechanisms and gene expression profiling for shikonin-induced apoptotic and necroptotic cell death in U937 cells. Chem Biol Interact 205: 119-127, 2013.

38 Zhang B, Han H, Fu S, Yang P, Gu Z, Zhou Q and Cao Z: Dehydroeffusol inhibits gastric cancer cell growth and tumorigenicity by selectively inducing tumor-suppressive endoplasmic reticulum stress and a moderate apoptosis. Biochem Pharmacol 104: 8-18, 2016.

39 Xu Y, Chiu JF, He QY and Chen F: Tubeimoside-1 exerts cytotoxicity in HeLa cells through mitochondrial dysfunction and endoplasmic reticulum stress pathways. J Proteome Res 8 : 1585-1593, 2009.

40 Rivera M, Ramos Y, Rodriguez-Valentin M, Lopez-Acevedo S, Cubano LA, Zou J, Zhang Q, Wang G and Boukli NM: Targeting multiple pro-apoptotic signaling pathways with curcumin in prostate cancer cells. PLoS One 12: e0179587, 2017.

41 Ham J, Lim W, Bazer FW and Song G: Silibinin stimluates apoptosis by inducing generation of ROS and ER stress in human choriocarcinoma cells. J Cell Physiol, 2017. doi: 10.1002/jcp.26069. [Epub ahead of print]

42 Zhang L, Hapon MB, Goyeneche AA, Srinivasan R, GamarraLuques CD, Callegari EA, Drappeau DD, Terpstra EJ, Pan B, Knapp JR, Chien J, Wang X, Eyster KM and Telleria CM: Mifepristone increases mRNA translation rate, triggers the unfolded protein response, increases autophagic flux, and kills ovarian cancer cells in combination with proteasome or lysosome inhibitors. Mol Oncol 10: 1099-1117, 2016.

43 Boelens J, Lust S, Offner F, Bracke ME and Vanhoecke BW: Review. The endoplasmic reticulum: a target for new anticancer drugs. In Vivo 21: 215-226, 2007.

44 Zanotto-Filho A, Dashnamoorthy R, Loranc E, de Souza LH, Moreira JC, Suresh U, Chen Y and Bishop AJ: Combined Gene Expression and RNAi Screening to Identify Alkylation Damage Survival Pathways from Fly to Human. PLoS One 11: e0153970, 2016.

45 Gifford JB and Hill R: GRP78 influences chemoresistance and prognosis in cancer. Curr Drug Targets, 2017. doi: 10.2174/1389450118666170615100918. [Epub ahead of print] 
46 Holtrup F, Bauer A, Fellenberg K, Hilger RA, Wink M and Hoheisel JD: Microarray analysis of nemorosone-induced cytotoxic effects on pancreatic cancer cells reveals activation of the unfolded protein response (UPR). Br J Pharmacol 162: 10451059, 2011.

47 Nawrocki ST, Carew JS, Pino MS, Highshaw RA, Dunner K Jr., Huang P, Abbruzzese JL and McConkey DJ: Bortezomib sensitizes pancreatic cancer cells to endoplasmic reticulum stress-mediated apoptosis. Cancer Res 65: 11658-11666, 2005.

48 Vanacker H, Vetters J, Moudombi L, Caux C, Janssens S and Michallet MC: Emerging Role of the Unfolded Protein Response in Tumor Immunosurveillance. Trends Cancer 3: 491-505, 2017.

49 Ojha R and Amaravadi RK: Targeting the unfolded protein response in cancer. Pharmacol Res 120: 258-266, 2017.

50 Cubillos-Ruiz JR, Bettigole SE and Glimcher LH: Tumorigenic and Immunosuppressive Effects of Endoplasmic Reticulum Stress in Cancer. Cell 168: 692-706, 2017.

51 Cerezo M and Rocchi S: New anti-cancer molecules targeting HSPA5/BIP to induce endoplasmic reticulum stress, autophagy and apoptosis. Autophagy 13: 216-217, 2017.

52 Wang J, Lee J, Liem D and Ping P: HSPA5 Gene encoding Hsp70 chaperone BiP in the endoplasmic reticulum. Gene 618: 14-23, 2017

53 So AY, de la Fuente E, Walter P, Shuman M and Bernales S: The unfolded protein response during prostate cancer development Cancer Metastasis Rev 28: 219-223, 2009.

54 Mohamed E, Cao Y and Rodriguez PC: Endoplasmic reticulum stress regulates tumor growth and anti-tumor immunity: a promising opportunity for cancer immunotherapy. Cancer Immunol Immunother 66: 1069-1078, 2017.

55 Rozpedek W, Pytel D, Mucha B, Leszczynska H, Diehl JA and Majsterek I: The Role of the PERK/eIF2alpha/ATF4/CHOP Signaling Pathway in Tumor Progression During Endoplasmic Reticulum Stress. Curr Mol Med 16: 533-544, 2016.

56 Cho YM, Jang YS, Jang YM, Chung SM, Kim HS, Lee JH, Jeong SW, Kim IK, Kim JJ, Kim KS and Kwon OJ: Induction of unfolded protein response during neuronal induction of rat bone marrow stromal cells and mouse embryonic stem cells. Exp Mol Med 41: 440-452, 2009.

57 Farooqi AA, Li KT, Fayyaz S, Chang YT, Ismail M, Liaw CC, Yuan SS, Tang JY and Chang HW: Anticancer drugs for the modulation of endoplasmic reticulum stress and oxidative stress. Tumour Biol 36: 5743-5752, 2015.
58 Guichard C, Pedruzzi E, Fay M, Marie JC, Braut-Boucher F, Daniel F, Grodet A, Gougerot-Pocidalo MA, Chastre E, Kotelevets L, Lizard G, Vandewalle A, Driss F and Ogier-Denis E: Dihydroxyphenylethanol induces apoptosis by activating serine/threonine protein phosphatase PP2A and promotes the endoplasmic reticulum stress response in human colon carcinoma cells. Carcinogenesis 27: 1812-1827, 2006.

$59 \mathrm{Zu} \mathrm{K}$, Bihani T, Lin A, Park YM, Mori K and Ip C: Enhanced selenium effect on growth arrest by BiP/GRP78 knockdown in p53null human prostate cancer cells. Oncogene 25: 546-554, 2006.

60 Notte A, Rebucci M, Fransolet M, Roegiers E, Genin M, Tellier C, Watillon K, Fattaccioli A, Arnould T and Michiels C: Taxolinduced unfolded protein response activation in breast cancer cells exposed to hypoxia: ATF4 activation regulates autophagy and inhibits apoptosis. Int J Biochem Cell Biol 62: 1-14, 2015.

61 Pierre N, Barbe C, Gilson H, Deldicque L, Raymackers JM and Francaux M: Activation of ER stress by hydrogen peroxide in C2C12 myotubes. Biochem Biophys Res Commun 450: 459463, 2014.

62 Bachhawat AK and Kaur A: Glutathione Degradation. Antioxid Redox Signal, 2017. doi: 10.1089/ars.2017.7136. [Epub ahead of print]

63 Kaur A, Gautam R, Srivastava R, Chandel A, Kumar A, Karthikeyan S and Bachhawat AK: ChaC2, an enzyme for slow turnover of cytosolic glutathione. J Biol Chem 292: 638-651, 2017.

64 Crawford RR, Prescott ET, Sylvester CF, Higdon AN, Shan J, Kilberg MS and Mungrue IN: Human CHAC1 Protein degrades glutathione, and mRNA induction is regulated by the transcription factors ATF4 and ATF3 and a bipartite ATF/CRE regulatory element. J Biol Chem 290: 15878-15891, 2015.

65 Mungrue IN, Pagnon J, Kohannim O, Gargalovic PS and Lusis AJ: CHAC1/MGC4504 is a novel proapoptotic component of the unfolded protein response, downstream of the ATF4-ATF3CHOP cascade. J Immunol 182: 466-476, 2009.

66 Liu Y, Hyde AS, Simpson MA and Barycki JJ: Emerging regulatory paradigms in glutathione metabolism. Adv Cancer Res 122: 69-101, 2014. 